\author{
Ministério da Educação \\ Universidade Tecnológica Federal do Paraná \\ Campus Londrina
}

\title{
O FENÔMENO DAS EMPRESAS UNICÓRNIOS BRASILEIRAS POR BOCK E HACKOBER
}

LONDRINA

2021 
THIAGO COSTA FERREIRA

\section{O FENÔMENO DAS EMPRESAS UNICÓRNIOS BRASILEIRAS POR BOCK E HACKOBER}

Trabalho de Conclusão de Curso apresentado como requisito parcial à obtenção do título de Bacharel em Engenharia de Produção, do Departamento de Engenharia de Produção, da Universidade Tecnológica Federal do Paraná, Campus Londrina Orientador: Prof. Me. Carlos Alberto Ribas

LONDRINA 


\section{TERMO DE APROVAÇÃO}

\section{TRABALHO DE CONCLUSÃO DE CURSO - TCC \\ O FENÔMENO DAS EMPRESAS UNICÓRNIOS BRASILEIRAS POR BOCK E HACKOBER}

Por

Thiago da Costa Ferreira

Monografia apresentada às 19 horas do dia 14 de maio de 2021 como requisito parcial, para conclusāo do Curso de Engenharia da Produção da Universidade Tecnológica Federal do Paraná, Cãmpus Londrina. O candidato foi arguido pela Banca Examinadora composta pelos professores abaixo assinados. Após deliberaçāo e conferidas, bem como achadas conforme, as alteraçōes indicadas pela Banca Examinadora, o trabalho de conclusão de curso foi considerado APROVADO.

Banca examinadora:

\begin{tabular}{|l|c}
\hline Prof. José Luis Dalto & Membro \\
\hline Prof. Bruno Samways dos Santos & Membro \\
\hline Prof. Carlos Alberto Ribas & Orientador \\
\hline \hline Profa. Silvana Rodrigues Quintllhano Tondato & Professor(a) responsável TCCII \\
\hline
\end{tabular}

Documento assinado eletronicamente por (Document electronically signed by) SILVANA RODRIGUES QUINTILAANO TONDATO, PROFESSOR DO MAGISTERIO SUPERIOR, em (at) 15/05/2021, as 12:39, conforme horário oficial de Brastia (according to official Brasilia-Brazil time), com fundamento no (with legal based on) art. 62,518 , do

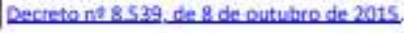

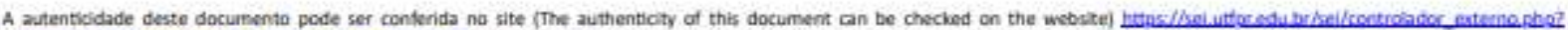




\section{AGRADECIMENTOS}

Agradeço e dedico este estudo às seguintes pessoas:

Minha mãe, Valquíria e meu pai, Cláudio, que além do suporte emocional, sempre me apoiaram e incentivaram a conquistar meus objetivos.

Meus irmãos, Raphael e Gustavo, sempre me guiando e orientando, principalmente quando o assunto é graduação e mercado de trabalho.

Minha namorada, Letícia, que nunca soltou minha mão e sempre me estimulou a continuar na minha luta do sonho grande.

Minhas cunhadas, Maria Cecília e Ana Luiza, por terem muita paciência comigo e com meus irmãos.

Meu professor e orientador, Carlos Ribas, por todos os ensinamentos, conselhos, e a dedicação para a realização dessa pesquisa. 


\section{RESUMO}

O empreendedorismo, com o surgimento da globalização e o desenvolvimento tecnológico, passou a ter níveis elevados de competitividade. Assim as empresas se tornaram obrigadas a investir, cada vez mais, em produtos, operações e serviços inovadores. Deste modo, investimentos passaram a ser distribuídos para desenvolver tecnologias disruptivas. Com isso, foi possível visualizar um crescimento rápido e exponencial de empresas tecnológicas, e assim, surgiu o fenômeno das empresas unicórnios. Neste sentido, através de uma pesquisa quantitativa e qualitativa, este estudo teve como objetivo descrever o surgimento desse fenômeno, descrevendo o ecossistema dos unicórnios globais e brasileiros. No caso das empresas unicórnios do Brasil, o trabalho analisou e comparou as 11 startups consideradas até o momento, unicórnios, com as hipóteses que favorecem o surgimento de novos unicórnios levantadas por Bock e Hackober (2020). Das quatro hipóteses identificadas pelos autores, três foram aprofundadas nessa pesquisa: agrupamentos de inovação, investimentos de Corporate Venture Capital e estratégias de crescimento inorgânico. Através desse estudo, foi possível concluir que, apesar das empresas unicórnios estarem distribuídas em 34 países, EUA e China ainda dominam cerca de $72 \%$ dessas empresas. Além disso, de 2019 a 2021, o Brasil teve um aumento de $550 \%$, em quantidade, e $769 \%$ em valor das empresas unicórnios. Em relação as hipóteses de Bock e Hackober, das 11 empresas estudadas, apenas 1 não se encaixa em nenhuma das três. Sendo que 8 dessas empresas se encontram na cidade de São Paulo, que foi considerada como o agrupamento inovador do Brasil, por oferecer condições únicas para empreender.

Palavras-chave: Unicórnios. Startups. Empreendedorismo. Inovação. 


\begin{abstract}
Entrepreneurship, with the rising of globalization and technological development, started to have high levels of competitiveness. Thus, companies have become obliged to invest more and more in innovative products, operations and services. In this way, investments started to be distributed to develop disruptive technologies. With that, it was possible to visualize a rapid and exponential growth of technological companies, and thus, the phenomenon of unicorn companies emerged. In this sense, through quantitative and qualitative research, this study aimed to describe the emergence of this phenomenon, describing the ecosystem of global and brazilian unicorns. In the case of unicorn companies from Brazil, the study analyzed and compared the 11 startups considered so far, unicorns, with the hypotheses that was related for the emergence of new unicorns raised by Bock and Hackober (2020). Of the four hypotheses identified by the authors, three were deepened in this research: innovation clusters, Corporate Venture Capital investments and inorganic growth strategies. Through this study, it was possible to conclude that, although unicorn companies are distributed in 34 countries, the USA and China still dominate around $72 \%$ of these companies. In addition, from 2019 to 2021 , Brazil had an increase of $550 \%$ in quantity and $769 \%$ in value of unicorn companies. Regarding the hypotheses of Bock and Hackober, of the 11 companies studied only 1 does not fit into any of the three. Eight of these companies are located in the city of São Paulo, which was considered as the economic cluster in Brazil, as it offers unique conditions for entrepreneurship.
\end{abstract}

Keywords: Unicorns. Startups. Entrepreneur. Innovation. 


\section{LISTA DE FIGURAS}

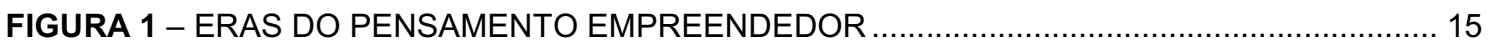

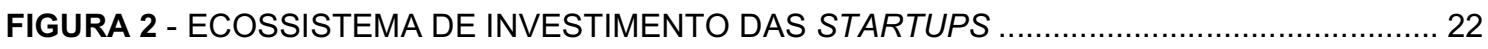

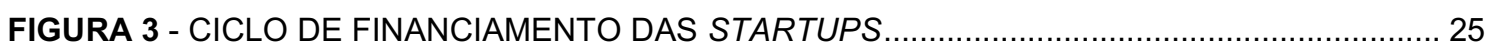

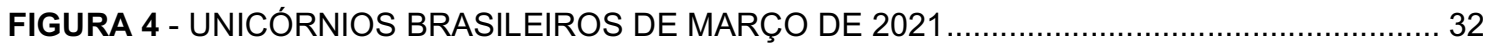

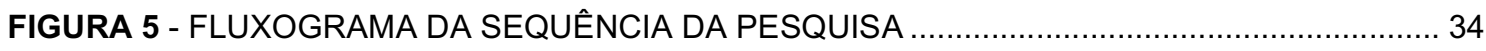

FIGURA 6 - EVOLUÇÃO DO FENÔMENO DAS EMPRESAS UNICÓRNIOS DO MUNDO ............... 36

FIGURA 7 - MAPA MUNDI DAS EMPRESAS UNICÓRNIOS

FIGURA 8 - QUANTIDADE DE UNICÓRNIOS POR DATA E PAÍS …............................................ 37

FIGURA 9 - SEGMENTAÇÃO DO VALUATION DOS UNICÓRNIOS POR DATA E PAÍS .................. 38

FIGURA 10 - EMPRESAS UNICÓRNIOS GLOBAIS POR ÁREAS DE ATUAÇÃO............................ 39

FIGURA 11 - EVOLUÇÃO DO FENÔMENO DAS EMPRESAS UNICÓRNIOS DO BRASIL.............. 40

FIGURA 12 - AS 11 EMPRESAS UNICÓRNIOS BRASILEIRAS ................................................ 41

FIGURA 13 - CHECK DAS EMPRESAS UNICÓRNIOS VS. HIPÓTESES DE BOCK E HACKOBER

(2020)

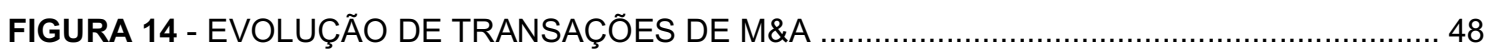




\section{SUMÁRIO}

1 INTRODUÇÃO

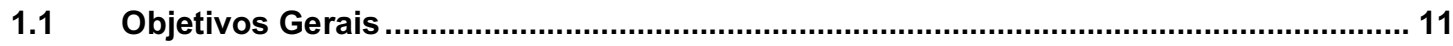

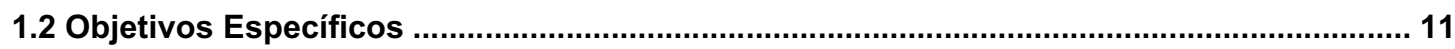

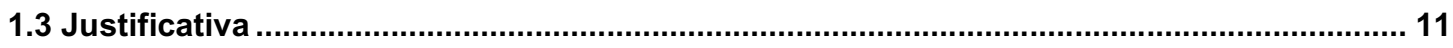

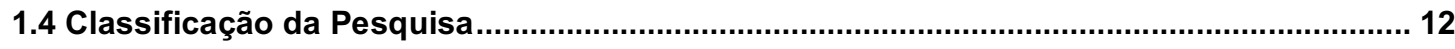

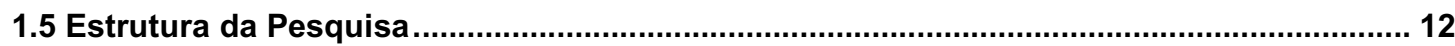

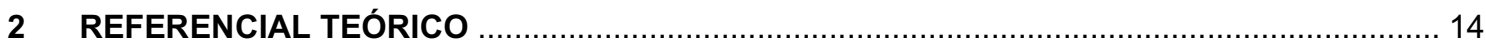

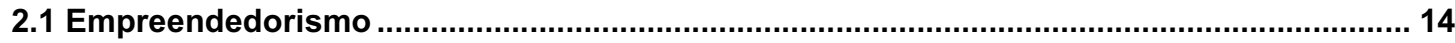

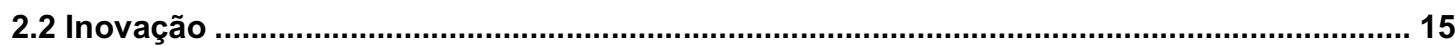

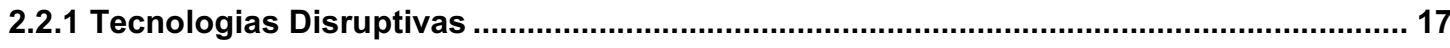

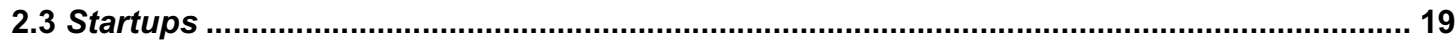

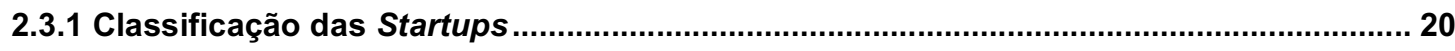

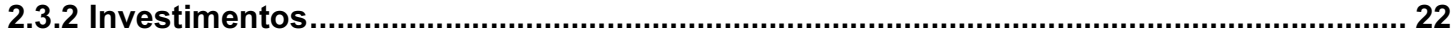

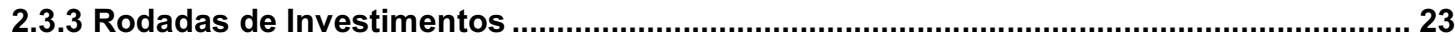

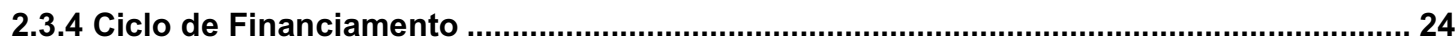

2.3.5 Modelos de Crescimento: orgânico (OG) e inorgânico (M\&A) ........................................ 25

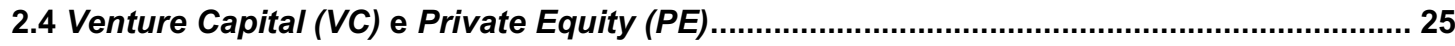

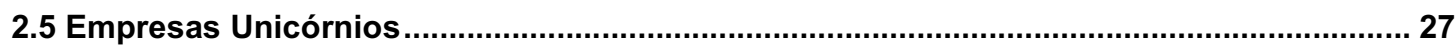

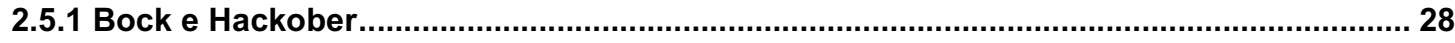

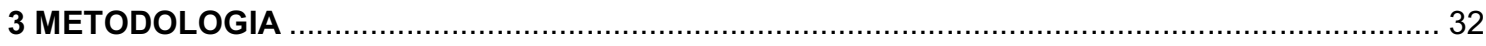

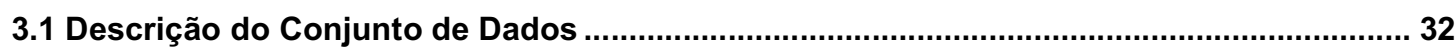

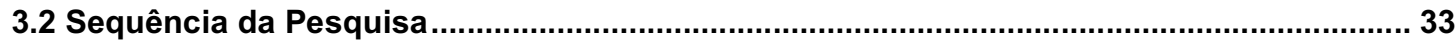

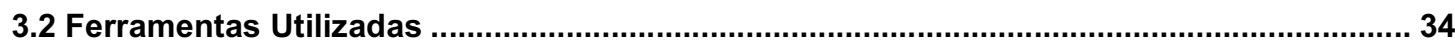

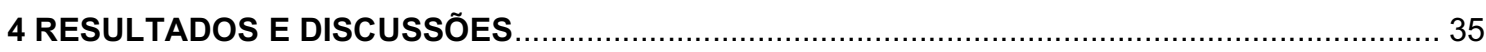

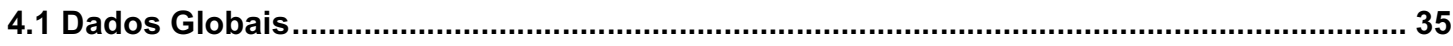

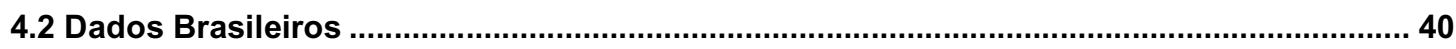

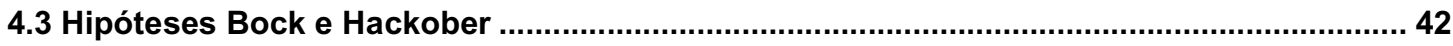

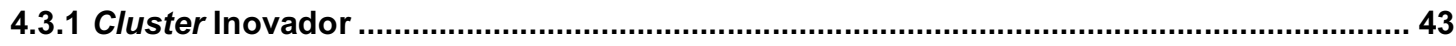

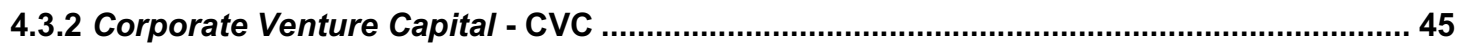

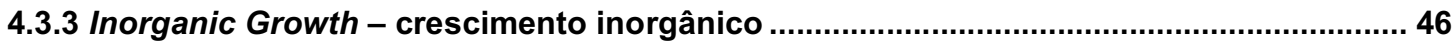


5 CONSIDERAÇÕES FINAIS

REFERÊNCIAS 


\section{INTRODUÇÃO}

O mundo moderno vem passando por profundas e aceleradas transformações econômicas, políticas e sociais, sendo que a globalização e desenvolvimento tecnológico foram os principais fatores que impulsionaram essas mudanças. Segundo Osborne e Gaebler (1994), as empresas e organizações não governamentais procuram se tornar mais flexíveis, inovadoras e empreendedoras, para, assim, enfrentar os desafios que surgem com a evolução de sociedade. Com o empreendedorismo não seria diferente. A forma de empreender também se transformou, o que pode ser verificado no final da década de 1990 nos Estados Unidos, quando as startups se tornaram responsáveis por tais transformações. As startups rapidamente difundiram seu conceito para o restante do mundo, sendo empresas normalmente de base tecnológicas, consideradas fontes de inovação, na qual buscam resolver os problemas da sociedade através de novas soluções e são marcadas principalmente por apresentarem um crescimento econômico mais exponencial do que o de empresas tradicionais.

No início do século XXI já era possível perceber um aumento no surgimento de startups e, ao mesmo tempo, empresas recentes atingindo um crescimento econômico sem precedentes. O termo "unicórnio", visando explicar esse fenômeno, surgiu pela primeira vez em um artigo do site Techcrunch, "Bem-vindo ao Clube dos Unicórnios" escrito por Aileen Lee (2013). O nome do animal mitológico foi utilizado para caracterizar as startups que superam o valor de um bilhão de dólares de valor de mercado e não estão cotadas em bolsas de valores.

É nítido que a revolução digital vinha atingindo uma escala nunca vista e um nível de impacto que nenhum negócio, governo ou indústria pode ignorar. A adoção de novas tecnologias de informação e o rápido desenvolvimento estão a criar oportunidades de negócios amplamente inovadoras (LUBIÁN; ESTEVES, 2017).

Com o aumento da tecnologia de informação e comunicação, no ecossistema empresarial, foi possível perceber um crescente aumento na criação de startups. Segundo Kerai (2017), as startups tecnológicas muitas vezes são consideradas como impulsionadoras de criação de valor, crescimento económico e criação de emprego. Aproveitando esta condição, elas buscam funcionar como inovações disruptivas de forma a corresponder às necessidades da sociedade não satisfeitas nos outros setores (ROY, 2018). 
Muitas startups normalmente têm seu negócio voltado para uma solução inovadora, portanto, na sua fase inicial é comum apresentar resultados negativos. Mas, da mesma forma, verifica-se, mesmo no early stage, a captação de grandes investimentos. Os unicórnios são efetivamente startups e, devido à incerteza de negócio das startups isso só é possível, atingir o valuation de um bilhão de dólares, pelo nível das suas avaliações, que muitas vezes estão alicerçadas nas suas perspectivas de crescimento (GÖBEL, 2016). A captação de investimentos é bastante comum entre as empresas unicórnios, segundo a consultoria CB Insight dos 346 unicórnios, ao redor do mundo, apenas um deles não fez nenhuma captação de investimento com venture capitals e/ou private equity $(0,29 \%)$.

Embora o interesse do público e da mídia neste subgrupo específico de empresas apoiadas por VC tenha aumentado desde 2010, a pesquisa acadêmica sobre este tópico permaneceu limitada. Assim, esta pesquisa visa mostrar os dados globais e brasileiros que representam este fenômeno e analisar as unicórnios do Brasil usando como base as hipóteses de Bock e Hackober.

\subsection{Objetivos Gerais}

Realizar um estudo descritivo do surgimento das empresas unicórnios do Brasil.

\subsection{Objetivos Específicos}

- Descrever, quantitativamente o cenário das empresas unicórnios do mundo.

- Descrever, quantitativamente, os 11 unicórnios brasileiros.

- Descrever o fenômeno das empresas unicórnios brasileiros pelas hipóteses de Bock e Hackober.

\subsection{Justificativa}

Na Teoria do Desenvolvimento Econômico, Arthur Lewis relata que a principal característica do desenvolvimento é o crescimento das empresas. Lewis aborda que o surgimento de um pequeno de grupo de pessoas que utilizam uma 
grande soma de capital para empreender acaba gerando uma grande quantidade de empregos (apud SANCHES, 2018). A visão do autor mostra o quanto o empresário está diretamente relacionado ao desenvolvimento econômico de um país. O empreendedorismo, muitas vezes, é considerado uma solução de fomento à economia. Assim, pode-se dizer que empresas unicórnios, por terem atingido um patamar tão elevado, acabam impactando diretamente de forma positiva a microeconomia da sua região de atuação. Além da geração de empregos, tais empresas são fundamentais na criação de tecnologias disruptivas, que surgem através de investimento em pesquisa e desenvolvimento. Para isso ocorrer, há a necessidade de mão de obra qualificada, resultando em investimento em escolas, universidades, cursos, entre outros.

Tendo em vista a notória importância das empresas unicórnios, esta pesquisa consiste em estudar e descrever o fenômeno das empresas unicórnios no mundo e no Brasil, para assim, verificar se os unicórnios brasileiros seguiram as hipóteses de favorecimento do surgimento de unicórnios anunciadas por Bock e Hackober (2020).

\subsection{Classificação da Pesquisa}

Procurando atingir os objetivos propostos neste estudo, foi realizada uma pesquisa qualitativa e quantitativa, pois através da análise de dados buscou analisar vantagens e compreender as questões investigadas. Fachin (2001) caracterizou esse tipo de pesquisa por relacionar mutuamente os dados mensuráveis e os dados definidos descritivamente.

A pesquisa, quantos aos objetivos, teve um caráter descritivo, pois buscou descrever as características do determinado fenômeno abordado (GIL, 2008). A análise de dados, o registro e a interpretação dos fatos do mundo não possuíram a interferência do autor da pesquisa.

\subsection{Estrutura da Pesquisa}

Após o capítulo introdutório, que descreve o assunto abordado na pesquisa, os objetivos gerais e específicos, a justificativa e a metodologia de pesquisa utilizada, é apresentado o referencial teórico. 
Inicialmente aborda-se o empreendedorismo, a inovação e as startups visando uma contextualização histórica dos principais temas envolvidos no surgimento das empresas unicórnios. Além disso, dentro de startups, apresenta-se as classificações das startups, investimento, rodadas de investimento, ciclo de financiamento e modelos de crescimento.

Ainda no referencial teórico, desenvolve-se sobre temas de extrema importância para compreender o fenômeno dos unicórnios, que são venture capital, private equity, empresas unicórnios e o estudo de Bock e Hackober (2020), responsável pelo levantamento de hipóteses que favorecem o surgimento de novas empresas unicórnios.

Em metodologia é descrito o conjunto de dados e, finaliza, com as ferramentas utilizadas durante a pesquisa. Já a apresentação dos dados globais e brasileiros das empresas unicórnios, juntamente, com a checagem das hipóteses de Bock e Hackober ocorre no quarto capítulo, resultados e discussões. Para finalizar, no quinto capítulo, considerações finais, demonstra a conclusão, as observações obtidas durante toda a pesquisa realizada e sugestões de futuras pesquisa. 


\section{REFERENCIAL TEÓRICO}

\subsection{Empreendedorismo}

Para muitos pesquisadores o empreendedorismo é algo relativamente novo, porém os pensamentos sobre a atividade exercida pelo empreendedor não são. Para Landström, Harirchi, Aström (2012), a função pode ser tão antiga como o intercâmbio e o comércio entre os indivíduos na sociedade, porém, o conceito não era discutido. A partir da evolução e complexidade dos mercados econômicos, o tema passou a interessar cientistas e pesquisadores.

Segundo os autores Landström e Benner (2010), a discussão se iniciou durante a Idade Média, após o fim das invasões bárbaras e a decadência do sistema feudal houve uma estabilidade para a população. A expansão comercial e populacional vinha contribuindo para o surgimento de uma nova classe social, a burguesia. Assim o feudalismo foi se afundando e um novo sistema econômico baseado na geração de lucro vinha conquistando espaço, o que propiciou a formação, aos poucos, de centros urbanos e ascensão da classe burguesa. Hisrich, Peter e Shepherd (2009) afiram que o termo empreendedor, nesse período, foi utilizado para descrever tanto os participantes quanto os administradores de grandes projetos de produção.

Para Landström e Benner (2010), um dos principais autores que abordaram as primeiras definições sobre o empreendedorismo foi Richard Cantillon, aproximadamente em 1680-1734. Richard descreveu o envolvimento dos empreendedores em trocas de mercadorias baseado na geração de lucro e decisões empresarias tomadas pela incerteza, inclusive uma das principais análises de Cantillon foi a ênfase sobre o "risco e as incertezas" (FILION, 1999; HISRICH; PETERS; SHEPHERD, 2009; BRUYAT; JULIEN, 2000). 
Figura 1 - Eras do Pensamento Empreendedor

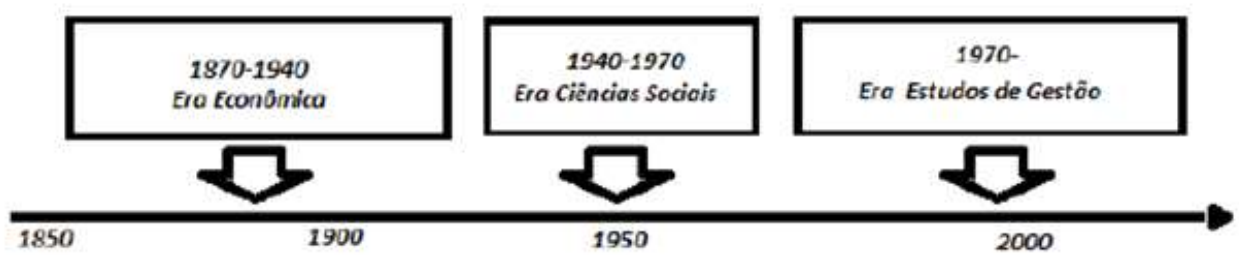

Fonte: Landstrom e Benner (2010, p. 20).

\subsection{Inovação}

Joseph Alois Schumpeter, um dos economistas mais importantes da primeira metade do século XX, foi o primeiro a considerar a importância das inovações tecnológicas para o desenvolvimento econômico do sistema capitalista. O economista acreditava que o sistema capitalista deveria analisado sob a ótica da produtividade e do crescimento, observando fortemente as inovações envolvidas nesse processo (SCHUMPETER, 1961).

Assim na sua obra Die Theorie der Wirschaftlichen Entwicklung, Teoria do Desenvolvimento Econômico, originalmente publicada em 1911, explica que o desenvolvimento econômico é conduzido pela inovação por meio de um processo complexo, nas quais as novas tecnologias substituem as antigas. Tal fenômeno foi denominado pelo Schumpeter de "destruição criadora" (MOTA, 2016) . O economista ainda dividiu as inovações em dois grupos:

- Inovações radicais: envolvem rupturas mais intensas, mudanças drásticas na maneira que o produto ou serviço é consumido modificando diretamente o modelo de negócios vigente. Exemplo: a criação da internet, ao analisar a época antes dessa criação, e depois percebe-se mudanças drásticas na sociedade capitalista; e

- Inovações incrementais: pequenas melhorias contínuas em produtos ou processos, representam um avanço tecnológico, porém não o suficiente para gerar uma ruptura com o já praticado pelo mercado. Exemplo: implementação do CD comum ao disco Blu-Ray.

Em 1982, Schumpeter propôs uma lista de cinco tipos de inovação: 

I. Introdução de novos produtos;
II. Introdução de novos métodos de produção;
III. Abertura de novos mercados;
IV. Desenvolvimento de novas fontes provedoras de matérias primas e outros insumos; e
V. Criação de novas estruturas de mercado em uma indústria.

O Manual de Oslo (OCDE, 2006) divide os tipos de inovação em quatro áreas: inovação de produto, de processo, de marketing e organizacional. Também mostra a importância das atividades de inovação, que são práticas adotadas dentro de uma instituição, ou não, visando sair de uma linha de pensamento tradicional. Tais atividades englobam etapas científicas tecnológicas, organizacionais, financeiras e comerciais. Apesar de serem nomeadas como atividades de inovação, não necessariamente são em si inovadoras, mas são essenciais para criação de novas metodologias que poderá resultar em algo inovador. O importante não é focar na inovação, e sim, buscar sempre meios diferentes do tradicional para assim, atingir a inovação. Nesse contexto verifica-se a importância das atividades que criam uma rotina de busca contínua por inovação em todos os âmbitos possíveis, para assim conseguir atingi-la.

A inovação de produto consiste em melhoramentos significantes no próprio produto ou na forma de como os serviços são oferecidos, incluindo a criação de novas funções para um determinado produto, o aumento da praticidade, a redução de custo, e até mesmo a criação de novos modais de logística (delivery realizado por drone).

Já inovação de processo é conceituada como uma nova maneira de se realizar um determinado processo, sem resultar em alterações significantes do produto ou serviço, obterá novas vantagens competitivas a essa empresa. Normalmente tais vantagens estão associadas a redução dos custos de fabricação do produto ou da realização de um determinado serviço. Essa atividade, na maioria das vezes, ocorre através da utilização de tecnologias inovadoras no processo, que podem ser completamente novas ou pequenos incrementos.

A inovação de marketing é definida como a criação de novos métodos de marketing, buscando melhor atender as demandas dos consumidores, facilitar a 
distribuição do produto e aumentar a força de vendas. Tal inovação atua em remodelagem de embalagens, reposicionamento do produto de uma empresa no mercado, estratégias de propaganda, fixação de preço, entre outros.

Já a inovação organizacional representa a criação e a implementação de novos métodos organizacionais, que consistem em melhorar a organização do local de trabalho, favorecendo relações internas e externas. Através dela, a organização busca melhorar o seu desempenho com redução de custos organizacionais, custos de operação e, simultaneamente, estimular a satisfação do funcionário no local de trabalho (aumento da produtividade) e ganhar acesso a ativos não transacionáveis (como conhecimento externo não codificado).

Junior Borneli, fundador da StartSe, fez uma análise entre a Teoria da Evolução das Espécies e empreendedores, empresas e startups. O empresário observou que, assim como no reino animal, a evolução nunca acontece em uma direção. Ele utiliza o exemplo da girafa de pescoço grande, que apesar de ser a conhecida atualmente, não foi a única opção evolutiva, mas foi a que deu certo. Dezenas de alternativas evolutivas falharam, porém quando uma delas se mostrou viável, a evolução seguiu naquela direção. Assim, pode-se observar o mesmo processo evolutivo nas empresas. Para a empresa conseguir se manter em um mercado altamente competitivo, inúmeras hipóteses serão testadas, e a maioria delas serão descartadas. Porém, ao alcançar a inovação, a empresa chega a um patamar acima dos seus concorrentes (STARTSE, 2019).

Tal analogia é essencial para entender o processo de inovação, sendo que a competitividade entre as empresas cria uma necessidade vital de mudança e adaptação. Aquela empresa que conseguir ser pioneira em uma inovação se destacará no mercado. Por fim, no estágio de desenvolvimento tecnológico que se atingiu hoje, a velocidade da evolução das empresas precisa ser imensa, para assim continuar competitiva no mercado. Isso resultou em uma grande corrida tecnológica, que foi pioneira para o surgimento das empresas unicórnios.

\subsubsection{Tecnologias Disruptivas}

Para Walsh e Linton (2000) as tecnologias disruptivas podem ser uma nova combinação de tecnologias existentes ou novas tecnologias cuja aplicação a áreas problemáticas ou novos desafios de comercialização (por exemplo, sistemas ou 
operações) podem causar grandes mudanças de paradigma de produto de tecnologia ou criar outros inteiramente novos. Kondratief (1935) e Schumpeter (1934) estavam entre os primeiros pesquisadores da área sugerindo que "Longas ondas de mudanças tecnológica e o processo de destruição criativa causada por novas tecnologias e novos conjuntos de habilidades causa a criação ou redefinição de empresas e mercados existentes".

O aumento de pesquisas nessa área causou o surgimento de diferentes argumentos para definir tecnologias disruptivas ou inovações descontínuas. As tecnologias disruptivas podem ser definidas como descobertas científicas capaz de romper as capacidades usuais de produto ou tecnologia e fornecem uma base para um novo estágio de competitividade. Já inovações descontínuas são considerados produtos, processos ou serviços que fornecem melhorias exponenciais no valor recebido pelo cliente. Para serem disruptivas devem ser consideras como terremotos, game change (mudança de jogo) ou tecnologias emergentes. A nomenclatura não é tão importante, mas o surgimento desses fenômenos é.

Kassicieh, Walsh, Cummings, McWhorter, Romig, Williams (2002) relatam que as tecnologias disruptivas tendem ocorrer naturalmente, porém só é possível identificar essas disrupções quando analisadas em retrospectiva. Para eles essas tecnologias fornecem um grande problema para um analista tecnológico exigindo um grau de percepção não necessário para tecnologias de sustentação que seguem estabelecendo paradigmas em uma determinada indústria.

As tecnologias disruptivas criam um novo crescimento nos setores em que penetram, permitindo que pessoas e empresas com conjuntos de habilidades diferentes forneçam valor de função escalonada para setores existentes ou criem novos a partir do valor que fornecem. Moore (1991), através de um exame das tecnologias disruptivas bem-sucedidas, sugere que elas fornecem valor excepcional para clientes menos satisfeitos com o paradigma de produto de tecnologia atual. Nas últimas décadas consumidores aceitaram produtos e serviços que só foram possíveis através de tecnologias disruptivas. Muitos desses produtos são menores, mais leves, mais baratos, mais flexíveis e convenientes, mais confiáveis, mais eficiente e, até mesmo, operacionalmente mais simples. As tecnologias disruptivas oferecerem uma mudança revolucionária na condução de processos e operações, entre elas estão: inteligência artificial, blockchain, internet das coisas, entre outras. 
Para autores empreendedores, como Kirchhoff e Walsh (2000), organizações bem-sucedidas e, aparentemente, bem gerenciadas falham ao não reconhecerem distinções entre tecnologias de sustentação e disrupção. Empresas empreendedoras, startups, sem uma base de cliente definida, podem tirar proveito das tecnologias disruptivas e, assim, redefinir os mercados atuais, enquanto as grandes empresas se recusam a canibalizar seus próprios mercados por meio do uso dessas tecnologias. Assim, essas empresas, ao se recusarem a redefinir seus clientes, utilizam de tecnologias de sustentação, que consiste em uma melhora do desempenho do produto dentro do paradigma atual de tecnologia.

\subsection{Startups}

Na década de 1990 surgiu o fenômeno das empresas ponto com, atuando na área de tecnologia da informação e comunicação (TIC), e fortemente associadas a evolução da internet. A valorização dessas empresas ocorreu de maneira rápida e incontrolável, o que atraiu novos olhares e investimentos para o setor de TIC. Em 1999, segundo a Investopedia, 39\% (trinta e nove por cento) de todos os investimentos de capital de risco estavam vinculados a empresas associadas a internet. Naquele ano, 295 (duzentos e noventa e cinco) dos 457 (quatrocentos e cinquenta e sete) IPOs eram de empresas vinculadas a internet.

Esse crescimento exponencial foi responsável pelo surgimento da dot.com bubble (bolha das empresas ponto com). A NASDAQ teve um crescimento de abaixo dos mil pontos em 1995 para mais de cinco mil pontos nos anos 2000. Com a explosão da bolha, a NASDAQ despencou de 5.048,62, em 10 de março de 2000, para 1.114,11 pontos, em 9 de outubro de 2002. O boom da bolha demonstrou que não significa que a ideia tem valor simplesmente por estar na internet. Porém, a crença em tecnologia e internet não foi enfraquecida. Apesar da queda de credibilidade para captar investimentos por parte dos venture capital, o movimento de startup só ganhou força. A internet e a tecnologia moderna possibilitaram o surgimento de novas oportunidades de negócios, e com isso, as startups começaram a se fortalecerem e consolidarem no mercado.

Mas no final das contas, o que é uma startup? A tradução da palavra é "começar", porém o conceito de uma empresa startup não é tão simples assim. Para Blank e Dorf (2012), ainda existem dificuldades, pois, durante anos, startup era 
considerada apenas como uma versão menor de empresas. Eric Ries, autor do livro "A Startup Enxuta" (2012), uma startup significa uma "instituição humana designada a entregar um novo produto ou um serviço sobre condições de extrema incerteza". Já Dave McClure, um dos fundadores do 500 Startups (venture capital responsável por realizar investimentos durante estágios iniciais dessas empresas), "uma startup é uma companhia que está confusa sobre o que o produto é, quem são seus consumidores e como fazer dinheiro". Já para Steve Blank, responsável pelo desenvolvimento da metodologia Customer Development (desenvolvimento do cliente), "startup é uma organização temporária usada para buscar um modelo de negócio escalonável e repetível".

Por esses três conceitos é possível identificar que uma startup, normalmente, está relacionada a uma ideia inovadora, um modelo de negócio para escalonar e com um orçamento limitado. Assim, é bastante comum startups realizarem rodadas de investimento para atrair capital, e até mesmo, know how dos seus investidores.

O termo scale-up é utilizado para classificar empresas que crescem de maneira escalável e acabam sustentando esse crescimento por pelo menos três anos. Assim, normalmente, esse termo é utilizado para nomear startups que já foram escalonadas. No entanto, várias empresas, mesmo após seu crescimento exponencial, continuam utilizando a nomenclatura startup. Vale ressaltar que nem sempre todas as scale-up, foram startups. Por outro lado, toda startup, por possuir em sua essência características como ser enxuta, escalável e inovadora, pode se tornar uma scale-up.

\subsubsection{Classificação das Startups}

Conforme o movimento startups foi ganhando forças, surgiu a necessidade de classificá-las em subgrupos de modo a facilitar o seu estudo. Assim, para a plataforma Startse, uma das maiores plataformas de startups do Brasil, a divisão dessas empresas é realizada de diversas maneiras, sendo que as principais classificações são relacionadas aos nichos de atuação e a relação aos tipos de negócios.

Logo, as startups podem ser classificadas pelo seu nicho de atuação: FinTech (mercado financeiro), HealthTech (saúde e medicina), EdTech (educação) e 
LawTech (direito). Essa divisão e a utilização do sufixo "Tech" são exclusivas de empresas startups, portanto, ao serem utilizadas para denominar uma empresa, pode ter certeza que esta é uma startup, ou já foi uma.

Já a classificação em relação aos tipos de negócio é realizada através das classes:

- $\quad$ Business to Business (B2B): negócios para negócios, as startups, dessa classe, possuem relações comerciais, exclusiva, com outras empresas. Um exemplo é o 99 Corp, uma empresa que fornece planos corporativos de transporte para outras empresas.

- $\quad$ Business to Consumer (B2C): negócios para consumidores, é uma empresa vendendo para um consumidor final. Um exemplo é o Nubank.

- Bussines to Business to Consumer (B2B2C): negócios para empresas para consumidores, em outras palavras, é quando uma empresa faz parceria com outra para realizar uma venda para o consumidor final. O iFood, é um exemplo claro dessa relação, no qual o aplicativo faz parcerias com restaurantes para realizar uma venda ao seu usuário.

- $\quad$ Business to Government (B2G): negócios para governo, é quando o governo contrata uma empresa, através de licitações, para a realização de um serviço ou produto. A 1Doc, é uma startup que busca aumentar a transparência e reduzir custos nas gestões municipais.

- $\quad$ Direct to Consumer e-commerce (D2C): direto ao consumidor através do comércio digital. Consiste na interação direta do consumidor com os fabricantes, portanto, os intermediários das negociações são retirados. Essa categoria é recente e vem surgindo várias empresas unicórnios com esse modelo de negócio. No Brasil, as empresas VTEX, 
QuintoAndar, Loft e MadeiraMadeira são unicórnios que utilizam o D2C e-commerce.

\subsubsection{Investimentos}

Ao iniciarem seu processo de estruturação e operacionalização, as startups iniciam, paralelamente, a captação de recursos. Porém, ao contrário das empresas tradicionais, no início de uma startup não existe ativos como garantia e, simultaneamente, o desejo de escalonar em tempo curto. Para Bengtsson (2013) a ausência de garantias pelas startups tem como resultado uma maior dificuldade na aquisição de empréstimos por meios tradicionais. Assim, essas empresas buscam por capital de risco, e, em troca, oferecem percentuais futuros para amenizar o risco assumido pelo investidor.

O estudo realizado por Ramalho, Furtado e Lara (2011), no $2^{\circ}$ Censo de Private Equity e Venture Capital - PENC (2011), o ecossistema, do investimento realizado nas startups, é dividido em 3 grandes grupos que, de maneira cooperativa, atuam na evolução dessas empresas ao longo de seu ciclo de desenvolvimento.

Figura 2 - Ecossistema de investimento das startups

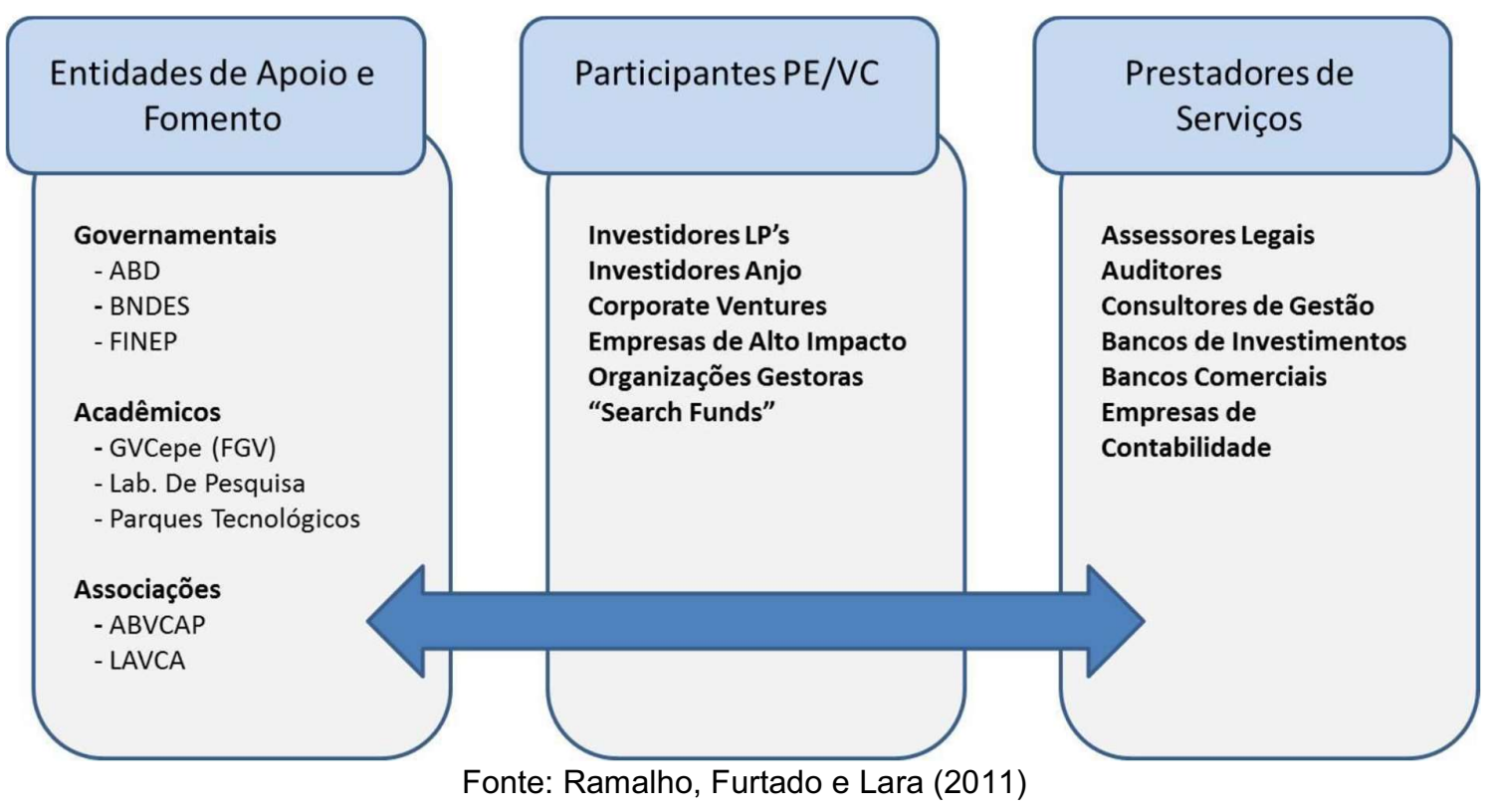


$\mathrm{Na}$ primeira categoria, entidades de apoio e fomento, identifica-se agências governamentais, instituições de ensino, associações, que auxiliam na criação e captação de investimentos iniciais em ideias que podem gerar novos negócios. Normalmente startups, em sua fase inicial, participam de programas relacionados a essa categoria, nesse caso nem sempre é um investimento financeiro, pode ser uma consultoria, suporte tecnológico, e, até mesmo, um espaço físico para começar. A partir da evolução e estruturação desses negócios, começam a surgir os primeiros resultados obtidos, assim passam a fazer parte do bloco dos participantes de Private Equity e Venture Capital. Nesse nível, as startups vão aportar capital para escalonar seu crescimento. Assim a empresa se consolida na participação do mercado, surgindo a necessidade dos prestadores de serviços, que auditam, contabilizam e certificam os negócios gerados e os valores ciados pela empresa.

\subsubsection{Rodadas de Investimentos}

Durante o crescimento de uma startup é possível identificar diversos tipos de investimento, cada um deles envolve uma etapa diferente. As rodadas de investimento consistem em fundraising, que é quando uma empresa busca um aporte de fundos. Vale ressaltar que rodadas de investimento é diferente de empréstimo, pois, no primeiro caso, a startup negocia parte das suas cotas aos investidores. Os estágios de investimentos, em startups, são bem definidos e começam com investidores-anjos, aceleradoras (pre-seed), investimento semente (seed) e, posteriormente, começam as séries $A, B, C$, etc.

Segundo a Anjos do Brasil, organização sem fins lucrativos fundada em 2011 que busca apoiar startups na fase de crescimento, conceitua investimento-anjo como investimento em uma empresa, que está na sua fase inicial, efetuado por pessoas físicas com capital próprio. Os investidores, através desse aporte, buscam agregar valor aos empreendedores por meio de know how e networking.

No investimento pre-seed o aporte é focado para garantir recursos para os primeiros estágios da vida da startup. Nessa fase que são realizados os primeiros testes e o Minimum Viable Product (MVP), produto minimamente viável, são lançados. O aporte de investimento é focado para garantir melhorias do produto. No Brasil, as rodadas de pre-seed variam entre $R \$ 100.000$ a $R \$ 700.000$. 
Já no tipo de investimento seed, capital de sementes, a startup já apresenta sinais de validação de produto. Assim, o foco do aporte é para encontrar o Product Market Fit (PMF), que é uma estratégia de marketing com vendas que visa avaliar o desempenho do produto em um determinado mercado. No Brasil, rodadas seed possuem um intervalo de $\mathrm{R} \$ 1$ a $\mathrm{R} \$ 5$ milhões.

Na rodada de investimento séries $\mathrm{A}$, a startup já apresenta uma sintonia entre mercado, produto e canal de distribuição. Assim, o aporte adquirido nessa fase possui como foco otimizar a base de usuários e desenvolver novas ofertas de produtos e serviços. Portanto essa rodada é uma oportunidade para dimensionar o produto em diversos nichos de mercados. Essa fase, geralmente, possui Venture Capital e Private Equity como investidores, os valores dos investimentos variam de $R \$ 5$ a $R \$ 40$ milhões.

Após a rodada de investimento séries $\mathrm{A}$, a startup só conseguirá o followon dos investimentos se possuir uma performance satisfatória relacionada a rodada de investimento anterior. Assim, a partir do investimento séries B os pontos analisados são: ganhos de mercado, geração de caixa, aquisições de empresas, etc.

Já no investimento séries $C$, os investidores procuram empresas com participação considerável no mercado, assim, o aporte de capital é focado para expansão internacional e aquisição de concorrentes para domínio de mercado. Nessa rodada a captação de capital varia em U\$100 a U\$250 milhões de dólares.

\subsubsection{Ciclo de Financiamento}

Mason e Harrison (2015) abordam o conceito da "escada rolante do financiamento", que consiste na busca, constante, da empresa por capital investidor. $\mathrm{Na}$ fase embrionária, a empresa busca subvenções ou capital para pesquisas da modalidade Família, Amigos e Fundadores (Family, Friends and Founder - 3Fs). Posteriormente, a partir do estágio inicial, buscam os investidores anjos, seguidos de VC e, por fim, a entrada no IPO - Oferta Pública Inicial. Esse fluxo foi definido por Blank (2013) 
Figura 3 - Ciclo de Financiamento das Startups

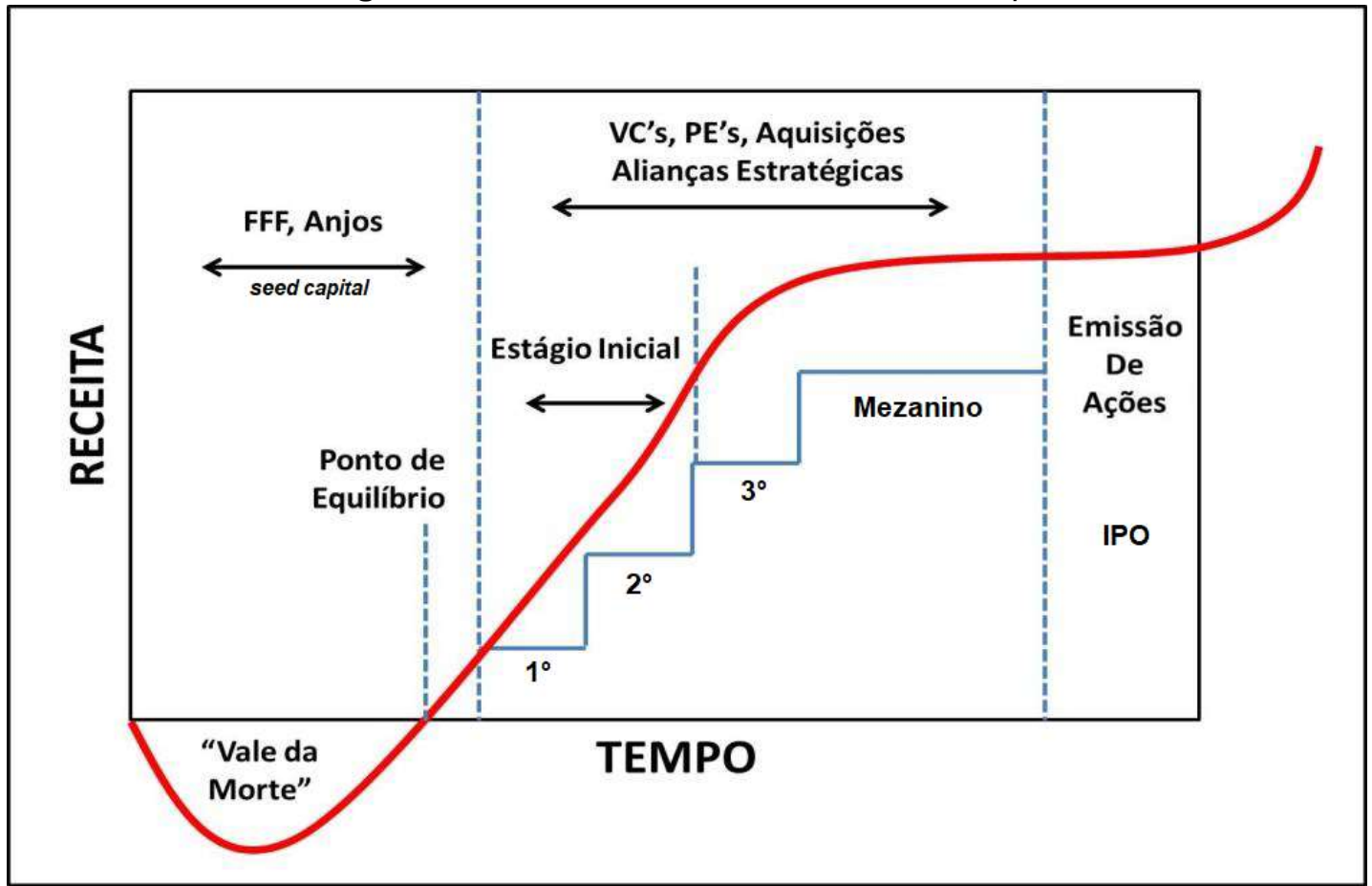

Fonte: Adaptada de Blank (2013)

\subsubsection{Modelos de Crescimento: orgânico (OG) e inorgânico (M\&A)}

Atualmente as empresas adotam dois tipos de modelos de crescimento, organic growth (OG) ou crescimento orgânico e o inorgânico. O primeiro consiste em um crescimento de forma natural, em outras palavras, isso consiste em um aumento da produção e das vendas. A empresa pode até adquirir capital de rodadas de investimento, mas essa captação é aplicada internamente para melhorar as operações adotadas pela companhia.

Já o modelo de crescimento inorgânico consiste na aquisição ou fusão de novos negócios para incrementar a operação de uma determinada empresa. Esse fenômeno é conhecido como $M \& A$ - mergers and acquisitions ou fusões e aquisições.

\subsection{Venture Capital (VC) e Private Equity (PE)}

Apesar da existência de diferentes tipos de investimentos envolvidos no surgimento de um unicórnio, os mais determinantes são oriundos de VC e PE. Por isso a importância de conceitua-los nessa pesquisa. 
Venture Capital significa, em português, capital de risco. Para a Associação Brasileira de Private Equity e Venture Capital (ABVCAP, 2014), VC é definido como um fundo de capital de risco que possuem como foco investir em empresas privadas de pequeno e médio porte que possuem alto potencial de crescimento, em troca do capital as empresas fornecem participações societárias. O fundo, após ganhos de capitais significativos a longo prazo, possui como objetivo final a revenda dessas participações.

Os fundos de VC, além de fornecer um aporte financeiro a essas empresas, visa atuar na profissionalização da gestão do negócio, contribuindo com know how e networking. Essa troca é fundamental para o sucesso do empreendimento e para o retorno dos fundos de investimento. Essa troca de conhecimento pode superar, em termos de valor, o próprio montante investido (CRIATEC, 2009).

No caso dos fundos de Private Equity consiste no equity investments (investimento em ações) de empresas que não estão listadas em ofertas públicas de valores. Os investimentos de PE possuem como característica baixa liquidez, retornos de longo prazo, e assimetria informacional, assim acabam possuindo riscos e, ao mesmo tempo, retornos mais elevados que os tradicionais, sendo classificados na categoria de ativos alternativos (RAMALHO; FURTADO; LARA, 2011). Segundo Carvalho, Ribeiro e Furtado (2009, p. 10) "os fundos de Private Equity investem em grandes empresas, com faturamento superior a dezenas de milhões ou mais, contando inclusive com mecanismos de alavancagem financeira (endividamento). Esse é o caso de empresas que estão se preparando para abrir capital na bolsa de valores, por exemplo."

No $2^{\circ}$ Censo Brasileiro - A Indústria de Private Equity e Venture Capital, Ramalho, Furtado e Lara (2011) definem como etapas do ciclo de PE/VC: o levantamento de recursos (fundraising), a seleção de investimentos (screening), a execução dos investimentos (investing), o monitoramento (monitoring), as saídas ou desinvestimentos (exits) e os retornos (returns).

Vale lembrar que o VC é um tipo de investimento de PE, porém a utilização da nomenclatura diferente, no decorrer dos anos, acabou distanciando esses investimentos. Tradicionalmente, os investimentos de PE eram divididos entre VC e Buyout. VC seria a compra de pequenas participações acionárias em empresas embrionárias, no estágio inicial de desenvolvimento. Já Buyout é quando ocorre a aquisição de uma empresa por parte de seus gestores. Assim, com o passar dos anos 
surgiu a necessidade de tratar esses termos como se fossem duas atividades distintas, o termo VC foi consolidado para representar a realização de investimentos em empresas que se encontravam em estágios iniciais, e, da mesma forma, PE para empresas em estágios mais avançados (RAMALHO; FURTADO; LARA, 2011).

Para os autores Aizenman e Kendall (2012), os termos de Private Equity e Venture Capital possuem usos conflitantes na imprensa financeira, para eles, isso ocorre por uma falta de definição. Assim, normalmente, definem VC de acordo com o tipo de investimento, que pode ser seed, startup, estágio inicial e expansão. Já PE é definido pelos investimentos de financiamento de risco e aquisições de empresas privadas.

\subsection{Empresas Unicórnios}

Em "Bem Vindo ao Clube dos Unicórnios" (TECHCRUNCH, 2013), Aileen Lee escolheu especificamente o termo para definir a raridade das empresas que haviam atingido o valor de um bilhão de dólares em menos de 10 anos de empresa, na época o artigo tinha 39 unicórnios, o que representava $0,07 \%$ das empresas, a partir de 2003, investidas por venture capital e startups de softwares.

Em 2015, Bill Gurley identificou o crescimento do fenômeno das empresas unicórnios. Bill verificou que apesar do ano de 2014 ter tido 273 IPOs, ano recorde desde a bolha ponto com, mais de 80 empresas privadas haviam entrado para - Clube dos Unicórnios, ou avaliadas acima de um bilhão de dólares. Simultaneamente, foi possível identificar um número crescente de empresas que se recusaram abrir o capital e continuaram como privadas. Assim, em relação aos períodos anteriores, a quantidade média de capital total levantado por empresas de unicórnio em rodadas de financiamento privado, excede a mediana de IPOs de base tecnológica (BROWN; WILES, 2015). Portanto é possível encontrar vários estudos se referindo a esses eventos de financiamento como "IPOs privados" (KESINGER et al. 2000; MILANESI, 2012; BROWN; WILES, 2015).

Com o passar dos anos empresas de tecnologias se espalharam ao redor do mundo, assim o fenômeno dos unicórnios deixou de ser somente dos Estados Unidos e se tornou mais frequente, porém a raridade continua. Em dezembro de 2016, iniciou-se o mapeamento do Clube dos Unicórnios pela empresa CB Insight, foram mapeadas 208 empresas que, ao todo, valiam 761 bilhões de dólares. Em março de 
2021, o clube conta com a participação de 603 empresas distribuídas em 34 países e que valem, no total, aproximadamente 2 trilhões de dólares.

\subsubsection{Bock e Hackober}

Bock e Hackober (2020) realizaram um estudo que analisou e identificou hipóteses que aumentam a probabilidade do surgimento de empresas unicórnios, para preencher a escassez de informações, dados e estudos relacionados ao tema, como identificado por eles e pelos autores Kaplan e Lerner (2016). A explicação para a lacuna pode ser explicada pelo fato de o surgimento dos unicórnios ser um fenômeno recente e relacionado aos VC. O estudo, então, levantou quatro hipóteses, e apenas uma não teve sua relação comprovada.

A primeira hipótese levantada foi Investor Reputation, ou reputação do investidor. A reputação pode ser considerada como um ativo intangível que se baseia no reconhecimento público da qualidade das atividades e resultados de uma empresa (SHAPIRO, 1983; RINDOVA et al., 2005; LEE et al., 2011). No caso dos VC, a reputação, a experiência e desempenho em investimentos anteriores é economicamente importante (ACHLEITNER et al., 2018), pois futuramente pode gerar rendas ao reduzir assimetrias de informação entre os participantes da negociação (HSU, 2004). Bock e Hackober (2020) concluíram que através dos resultados empíricos obtidos por sua pesquisa, não encontraram relações significantes entre a reputação dos investidores e a probabilidade do surgimento de novos unicórnios. Por fim, definiram a reputação do investidor como um critério difícil de ser mensurado. Assim, eles sugeriram que novas variáveis devem ser consideradas em pesquisas futuras para analisar essa hipótese.

A segunda hipótese consiste na existência de Economic Clusters, ou agrupamentos econômicos. Pesquisas anteriores mostraram diversos fatores que favoreciam o estabelecimento de novos empreendimentos em certas áreas geográficas, levando a formação de agrupamentos de inovação. Originalmente, foram identificados três fatores que facilitam a criação de agrupamentos: universidades e instituições de pesquisa, grandes empresas e governo (LEYDESDORFF; ETZKOWITZ, 1996). Porém, estudos mais recentes demonstram que o surgimento de agrupamentos é muito mais complexo e aplica a teoria de redes complexas para 
explicar os princípios operacionais dos cluster de inovação (FERRARY; GRANOVETTER, 2009).

Para os autores Khan e Ghani (2004), os agrupamentos oferecem condições únicas para novos empreendimentos que consistem em uma rede de empresas geograficamente concentradas. Portanto, ao serem fundados dentro de um cluster, os empreendimentos vão ter acesso, em estágios iniciais, a marketplaces, potencial consumidores de produtos inovadores, o que permite um feedback rápido e mais eficiente a respeito das funcionalidades de seus produtos (GILBERT et al. 2008). Assim, essas empresas devem ter uma alta capacidade de adaptação de seus produtos e processos para seus consumidores. Essa é uma linha de pensamento e argumento que diz que agrupamentos forçam novos empreendimentos a serem mais competitivos por possuírem uma competitividade maior nessa região, mas também facilitam o comportamento de diferenciação, pois os empreendedores podem reconhecer lacunas em seus produtos ou serviços existentes e, assim, preenchê-los fornecendo novos produtos ou serviços (GILBERT et al. 2008). Para Castilla (2003), agrupamentos tecnológicos e inovadores apresentam uma densidade elevada de investidores de VC, fornecendo financiamento necessários para novos empreendimentos.

Porém o estudo de Bock e Hackober identificou que cluster econômico possui um suporte limitado ao surgimento de novos unicórnios. Os autores ressaltaram, através de uma comparação entre os cluster dos EUA e da China, que o Vale do Silício é a única região que possui um efeito significativo na probabilidade de nascerem novas empresas unicórnios. Isso só ocorre, pois há uma combinação de boas condições de empreendedorismo e empreendimentos de qualidade. Nessa região, além de uma grande quantidade de investidores de capital de risco, é possível encontrar os melhores institutos de pesquisa, mão de obra qualificada e diversas inovações tecnológicas (BOCK; HACKOBER, 2020).

A terceira hipótese consiste no fato de as empresas terem como investidores CVC, Corporate Venture Capital ou capital de risco corporativo. Investidores CVC consistem em um fundo criado por uma empresa para investir em startups ou outros negócios. Possuem objetivos e condições diferentes de investidores independentes de VC. Metas e objetivos para CVCs podem ser generalizados apenas até certo grau, devido ao fato de que os programas CVC são tão únicos quanto suas empresas controladoras. Porém, CVC e VC possui um ponto 
em comum, em vez de ser apenas uma atividade financeira, os investidores CVC podem ser considerados uma combinação de operações estratégicas e financeiras (BLOCK et al., 2018; ROSSI et al., 2017). Na maioria dos investimentos, eles buscam obter acessos a novas tecnologias, novos mercados e alta qualificação de funcionários. Normalmente, essas tentativas incluem alavancar as inovações dos empreendimentos (GALLOWAY et al., 2017). Para as empresas que estão sendo investidas, o CVC oferece um acesso a ativos não financeiros da empresa-mãe. Esses ativos incluem know how, infraestrutura para o desenvolvimento do produto, fabricação, suporte jurídico, vendas, distribuição, atendimento ao cliente, entre outras (CHESBROUGH, 2000; NARAYANAN et al., 2009; PARK et al., 2012; CHEMMANUR et al., 2014). Ao oferecerem como suporte esses ativos, o CVC pode facilitar o desenvolvimento do empreendimento e, ao mesmo tempo, minimizar possíveis falhas durante seu processo de crescimento. Rossi et al. (2017) descobriram que os investidores corporativos se envolvem com empreendimentos de uma forma mais significativa, conectando-os com um ecossistema empresarial mais amplo e sofisticado. Bock e Hackober (2020) tiveram como resultado uma forte inter-relação entre os CVC e a probabilidade de sucesso dos empreendimentos, e consequentemente, o surgimento de novas empresas unicórnios.

A quarta e última hipótese, consiste na Growth Strategy ou estratégias de crescimento. Filloux (2014) relatou o fato de o Airbnb atingir um valor de mercado de 30 bilhões de dólares sem ter nenhum ativo relevante e ainda pelo fato de terem gastos quase 4 bilhões de dólares de fundos sem ter um modelo de negócios de alta tecnologia ou pesquisa intensiva. Mas, ao analisar de perto as empresas unicórnios e candidatos em potencial, é possível verificar que grande parte de sua avaliação foi e é baseada em participação de mercado e fortes taxas de crescimento. Isso ocorre, principalmente, por investidores aceitarem taxas de crescimento como substituto de valor, e para se sustentarem buscam aumentar os usuários, o envolvimento, a aquisição de clientes, as taxas de retenção e as receitas. Assim, os investidores se sentem confortáveis para absorverem possíveis perdas caso se deparem com uma chance de travar uma "posição para gerar lucros quase monopolísticos e, por extensão, enormes ganhos de capital" (KENNEY; ZYSMAN, 2019, p. 46).

As estratégias de crescimento inorgânico, baseada em fusões e aquisições ou $M \& A$, é do domínio das private equity e venture capital a fim de gerar valor (HAMMER et al., 2017). Esse tipo de estratégia permite um desenvolvimento 
próprio, uma vez que os empreendimentos precisam de capital para executar aquisições adicionais, e se tornarem, devido a um maior marketshare, mais atrativas para receberem investimentos. O empreendimento ou unicórnio em potencial precisa de um financiamento inicial para dispor do capital necessário para a realização do M\&A (HAMMER et al. 2017). Para os autores Kaplan e Stromberg (2000), é sensato dizer que os investidores são capazes de identificar startups promissoras e, assim, suportá-las em estratégias de crescimento inorgânico para ganharem, de maneira mais rápida, participações de mercado.

Bock e Hackober (2020) mostraram que estratégias de crescimento agressivas e inorgânicas estão impulsionando o nível de avaliação e, portanto, é uma estratégia favorecida do ponto de vista do investidor. Como uma extensão da pesquisa existente (KENNEY; ZYSMAN, 2019), essa suposição não se aplica apenas a modelos de negócios baseados em plataforma, mas parece ser aplicável a todos os unicórnios. 


\section{METODOLOGIA}

Neste capítulo é descrito a base de dados das empresas unicórnios do mundo, a apresentação do fluxograma do estudo na sequência de pesquisa e as ferramentas que foram utilizadas.

\subsection{Descrição do Conjunto de Dados}

Para a realização do estudo foi utilizado um mapeamento das empresas unicórnios do mundo, realizado pela $C B$ Insight, empresa de análise de negócios responsável por fornecer inteligência de mercado sobre empresas privadas e atividades de investidores. Frequentemente o banco de dados é atualizado, portanto, para analisar a evolução das empresas unicórnios no Brasil e no mundo, foi necessário adquirir dados em diferentes datas: 08 de maio de 2019, 04 de março de 2020, 31 de dezembro de 2020 e 18 de março de 2021. Os dados utilizados foram obtidos no decorrer de dois anos de acompanhamento das análises realizadas referentes as empresas unicórnios.

Os dados foram obtidos através do formato Planilha do Microsoft Excel. Por meio desse banco de dados foi possível realizar um estudo da evolução do surgimento das empresas unicórnios no Brasil e, assim, identificar os 11 unicórnios mais recentes, que foram analisados juntamente com as hipóteses de Bock e Hackober.

Figura 4 - Unicórnios brasileiros de março de 2021

\begin{tabular}{|l|l|l|l|l|}
\hline Companhia & País & Categoria & Valuation (\$B) & Investidores \\
\hline Nubank & Brasil & Fintech & $\$ 25.00$ & Sequoia Capital, Redpoint e.ventures, Kaszek Ventures \\
\hline Wildlife Studios & Brasil & Outros & $\$ 3.00$ & Benchmark, Bessemer Venture Partners \\
\hline Creditas & Brasil & Fintech & $\$ 1.75$ & Kaszek Ventures, Amadeus Capital Partners, Quona Capital \\
\hline VTEX & Brasil & E-commerce \& direto ao consumido $\$ 1.70$ & Riverwood Capital, Gavea Investimentos, Endeavor \\
\hline Movile & Brasil & Celular e telecomunicações & $\$ 1.00$ & Innova Capital - FIP, 3G Capital Management, Prosus Ventures \\
\hline iFood & Brasil & Lógistica, cadeia de suprimentos e d $\$ 1.00$ & Movile, Just Eat, Naspers \\
\hline Loggi & Brasil & Lógistica, cadeia de suprimentos e d $\$ 1.00$ & Qualcomm Ventures, SoftBank Group. Monashees+ \\
\hline QuintoAndar & Brasil & E-commerce \& direto ao consumido $\$ 1.00$ & Kaszek Ventures, General Atlantic, SoftBank Group \\
\hline EBANX & Brasil & Fintech & $\$ 1.00$ & FTV Capital, Endeavor \\
\hline Loft & Brasil & E-commerce \& direto ao consumido $\$ 1.00$ & Monashees+, Andreessen Horowitz, QED Investors \\
\hline MadeiraMadeira & Brasil & E-commerce \& direto ao consumidor $\$ 1.00$ & Flybridge Capital Partners, SoftBank Group, Monashees+ \\
\hline
\end{tabular}

Fonte: Autor (2021)

Na Figura 4 é possível verificar como é a disposição dos dados na planilha fornecida pela $C B$ Insight. No banco de dados original, as informações estão 
disponibilizadas em inglês, sendo necessário a realização da tradução destes. Vale lembrar que as quatro planilhas utilizadas nesse estudo, foram obtidos de forma gratuita na própria plataforma da CB Insight.

\subsection{Sequência da Pesquisa}

Primeiramente selecionou e acompanhou o banco de dados das empresas unicórnios da CB Insight por, aproximadamente, dois anos. Conforme descrito no item 3.1, os dados foram obtidos no formato Planilha do Microsoft Excel, e foi necessário realizar a tradução de alguns termos do inglês para o português.

Posteriormente, através das fórmulas "countif" e "sumifs", do próprio Excel, efetuaram a compilação dos dados em geral. Assim, foi possível segmentar as informações obtidas em dados globais e dados brasileiros. Posteriormente, realizouse gráficos para o mapeamento desses dados.

Desse modo, utilizou os dados brasileiros para identificar as 11 empresas unicórnios brasileiras, e assim, analisar o fenômeno dessas empresas através das hipóteses de Bock e Hackober (2020). Consequentemente, através de notícias e informações obtidas, foi possível apresentar quais hipóteses influenciaram, ou foram determinantes, no surgimento dos unicórnios brasileiros.

Na Figura 5 é apresentado o fluxograma que resume a sequência da pesquisa realizada. 
Figura 5 - Fluxograma da Sequência da Pesquisa

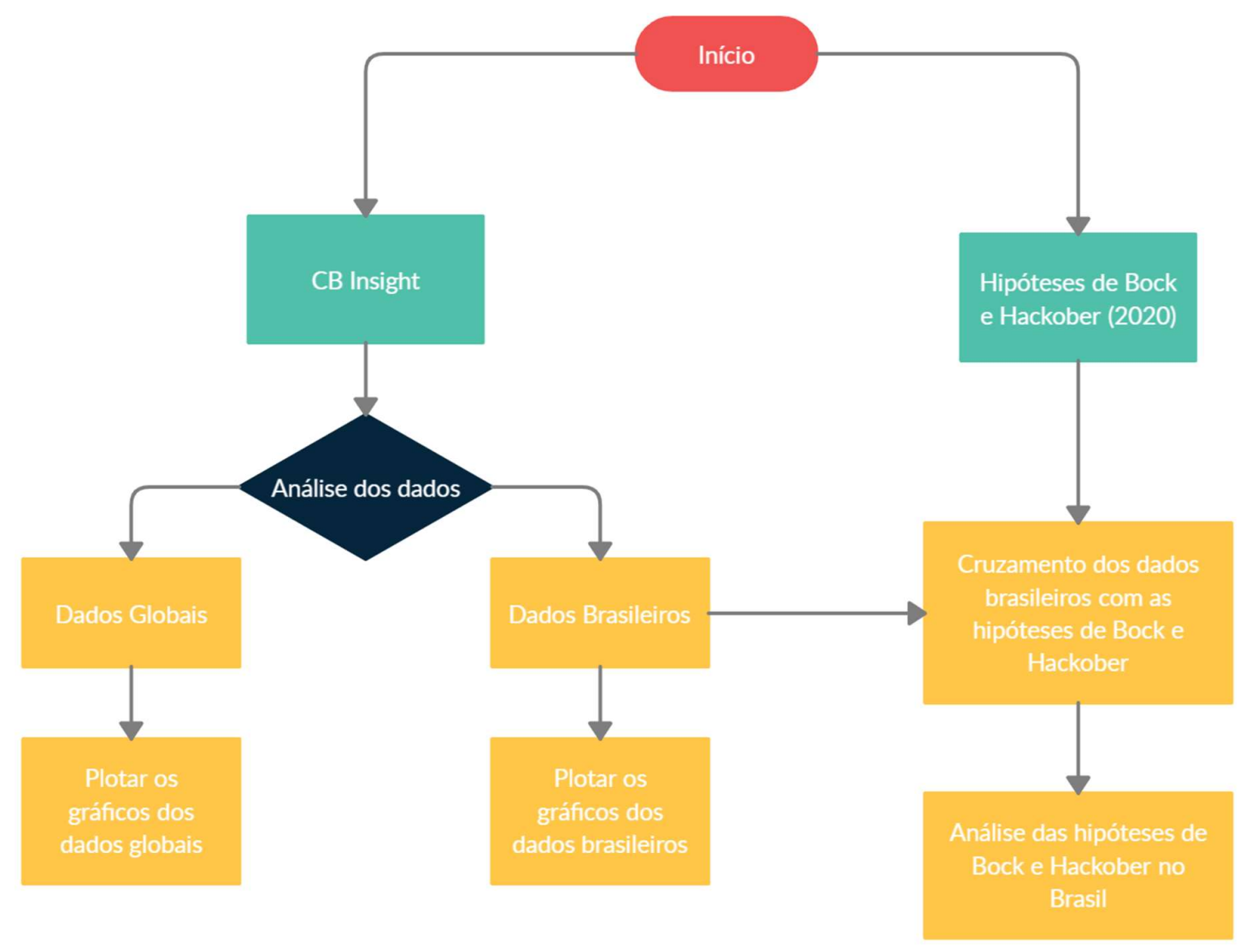

Fonte: Autor (2021)

\subsection{Ferramentas Utilizadas}

Os dados da planilha da $C B$ Insight foram baixados no formato Planilha do Microsoft Excel, formato padrão do programa, e foram tratados no próprio Excel. Como os dados estão disponibilizados em inglês, iniciou-se pelo processo de tradução. Posteriormente realizou o mapeamento da quantidade e o valution das empresas unicórnios por países. Foi aplicado a técnica Paretto para visualizar os países que eram mais determinantes no fenômeno. Realizou-se esse procedimento nas quatro planilhas, para no fim juntar as informações obtidas em um só arquivo e, assim, mapear a evolução desse fenômeno nos quatro períodos analisados.

Para a elaboração de gráficos e tabelas, também foi utilizado o programa Microsoft Excel. 


\section{RESULTADOS E DISCUSSÕES}

Neste capítulo são discutidos e avaliados os dados obtidos pela análise das quatro planilhas da $C B$ Insight. Para facilitar o estudo, essa etapa será dividida em três partes: a primeira analisou dados globais, já a segunda, apenas dados locais do Brasil, e para finalizar, realizou-se um estudo para verificar se o cenário brasileiro, das empresas unicórnios, respeitou as hipóteses de Bock e Hackober (2020).

Os dados foram organizados com o objetivo de apresentar o processo de evolução do fenômeno de surgimento das empresas unicórnios. Assim, cada planilha passou pelo mesmo processo de análise, e no final, realizou-se um comparativo dos dados tratados para descrever o surgimento dessas empresas no período entre 08 de maio de 2019 a 18 de março de 2021.

\subsection{Dados Globais}

Na Figura 6 é possível verificar a evolução dos fenômenos das empresas unicórnios no mundo. Em maio de 2019, o mundo possuía 346 empresas que, juntas, valiam cerca de $\$ 1151$ bilhões de dólares. Em março de 2020, o banco de dados mapeou 451 empresas com um valor de mercado de $\$ 1340.80$ bilhões de dólares. Em dezembro de 2020, 507 empresas que valiam \$1589,95 bilhões de dólares. Já em março de 2021, o banco de dados identificou 603 unicórnios com um valuation de $\$ 2004,62$ bilhões de dólares.

Assim, dentro desse intervalo de quase dois anos, o fenômeno dos unicórnios no mundo teve um crescimento de $74,28 \%$ em relação a quantidade de empresas que atingiram o valor de \$1 bilhão de dólares. Já em relação ao valor da soma dos valuation, houve um crescimento de $74,16 \%$. 
Figura 6 - Evolução do fenômeno das empresas unicórnios do mundo

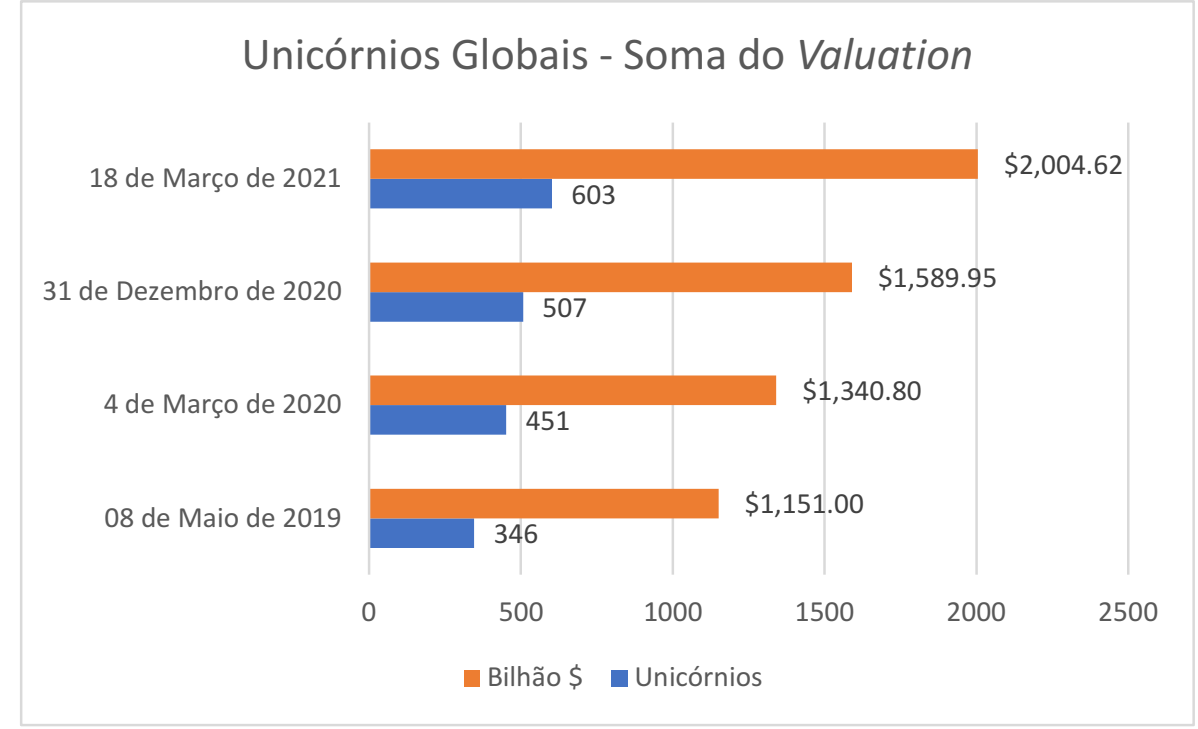

Fonte: Autor (2021)

Em março de 2021, 34 países distribuídos ao redor do mundo (Figura 7), possuíam, ao menos, uma empresa unicórnio. Porém, 11 países são responsáveis por, aproximadamente, $95 \%$ das empresas unicórnios do mundo em quantidade e em bilhões de dólares (soma dos valuation).

Figura 7 - Mapa Mundi das Empresas Unicórnios

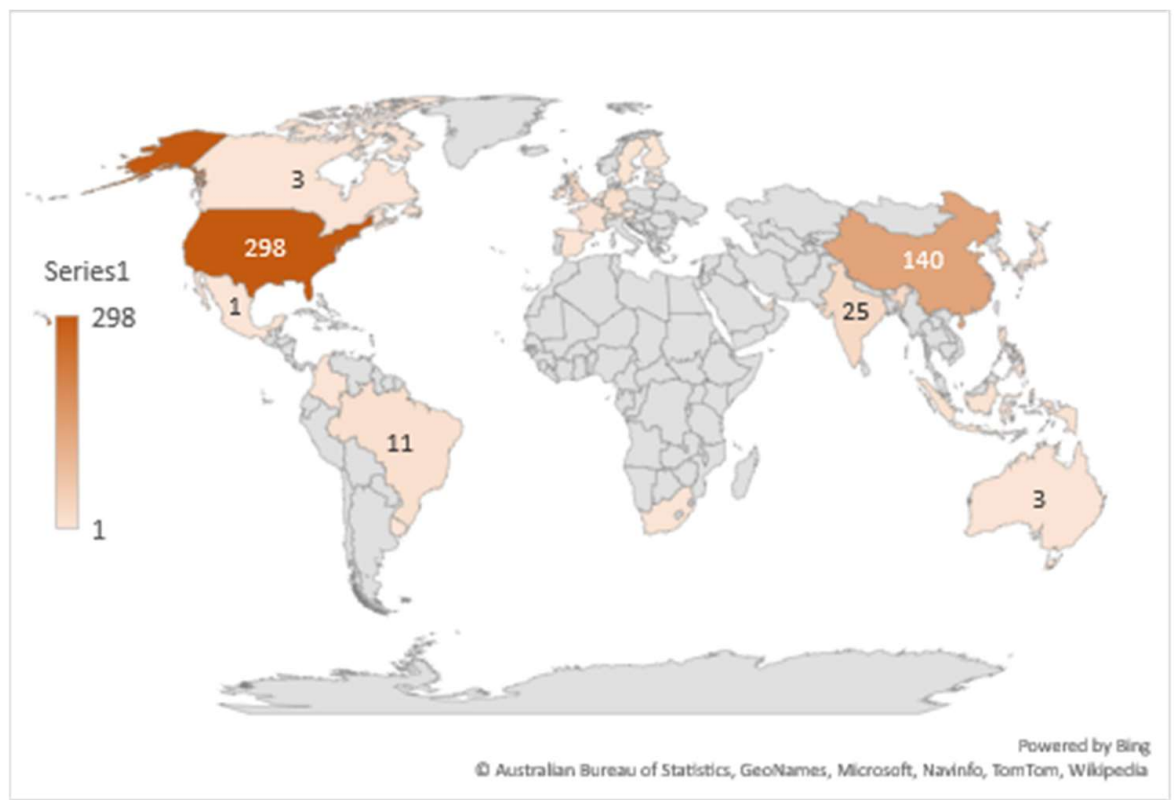

Fonte: Autor, 2021. 
Para facilitar a leitura dos gráficos, nas Figuras 8 e 9, utilizou-se os dados referentes aos 11 países determinantes no surgimento das empresas unicórnios.

Figura 8 - Quantidade de Unicórnios por Data e País

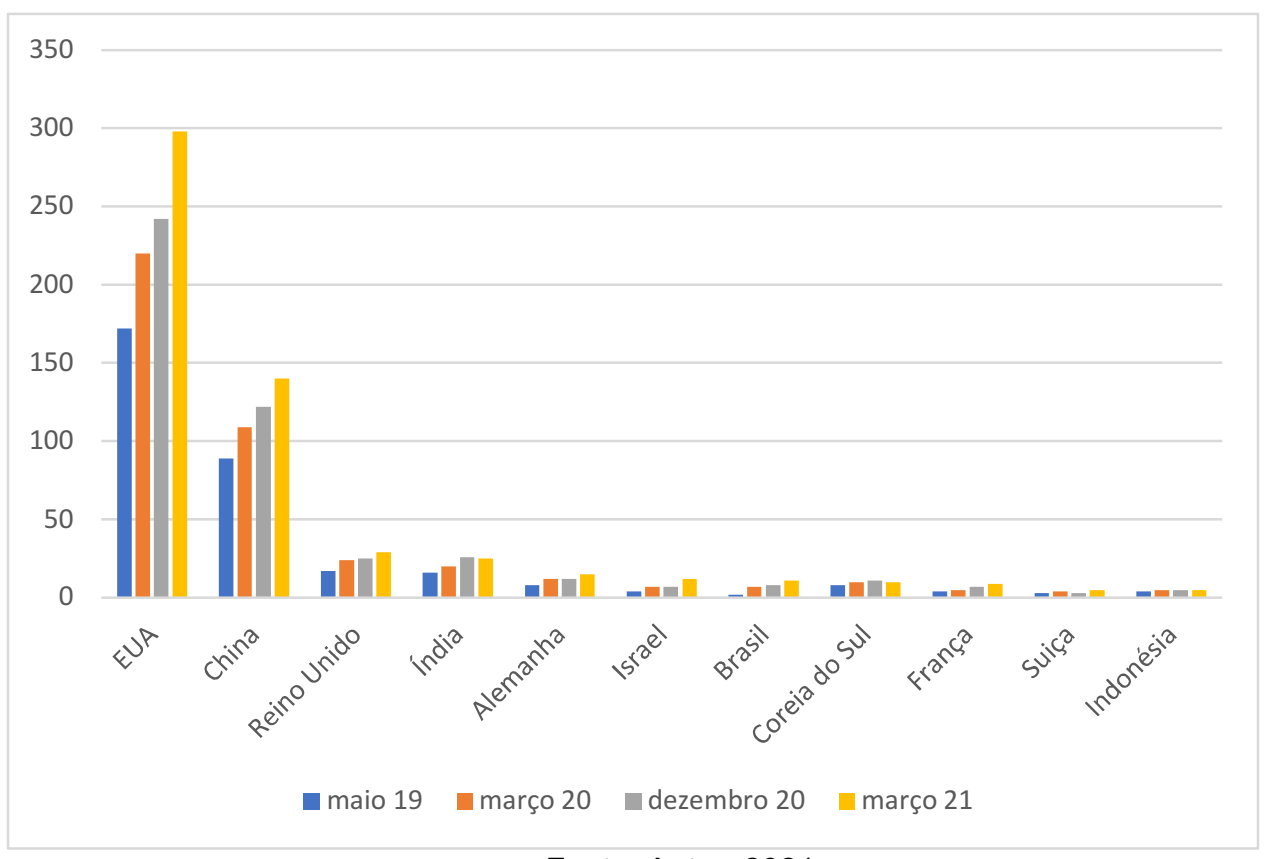

Fonte: Autor, 2021

\section{Nas Figura 8 e Figura 9}

é possível visualizar a evolução de cada país, durante o intervalo de quase dois anos, nas datas analisadas pelo estudo. Portanto, é possível identificar a predominância dos EUA e da China no crescimento desse fenômeno. No início do acompanhamento dos dados do estudo, em maio de 2019, os EUA possuíam 49,7\%, em quantidade, e 47,8\%, da soma de valor, das empresas unicórnios do mundo. Já a China, na mesma época, possuía $25,7 \%$, em quantidade, e $27,5 \%$, em valor, das empresas unicórnios. Atualmente, dados referentes a março de 2021, os EUA possuem $49,4 \%$, em quantidade, e $50 \%$, em valor, já a China, possui $23,2 \%$, em quantidade, e $27 \%$, em valor, das empresas unicórnio do mundo. 
Figura 9 - Segmentação do Valuation dos Unicórnios por Data e País

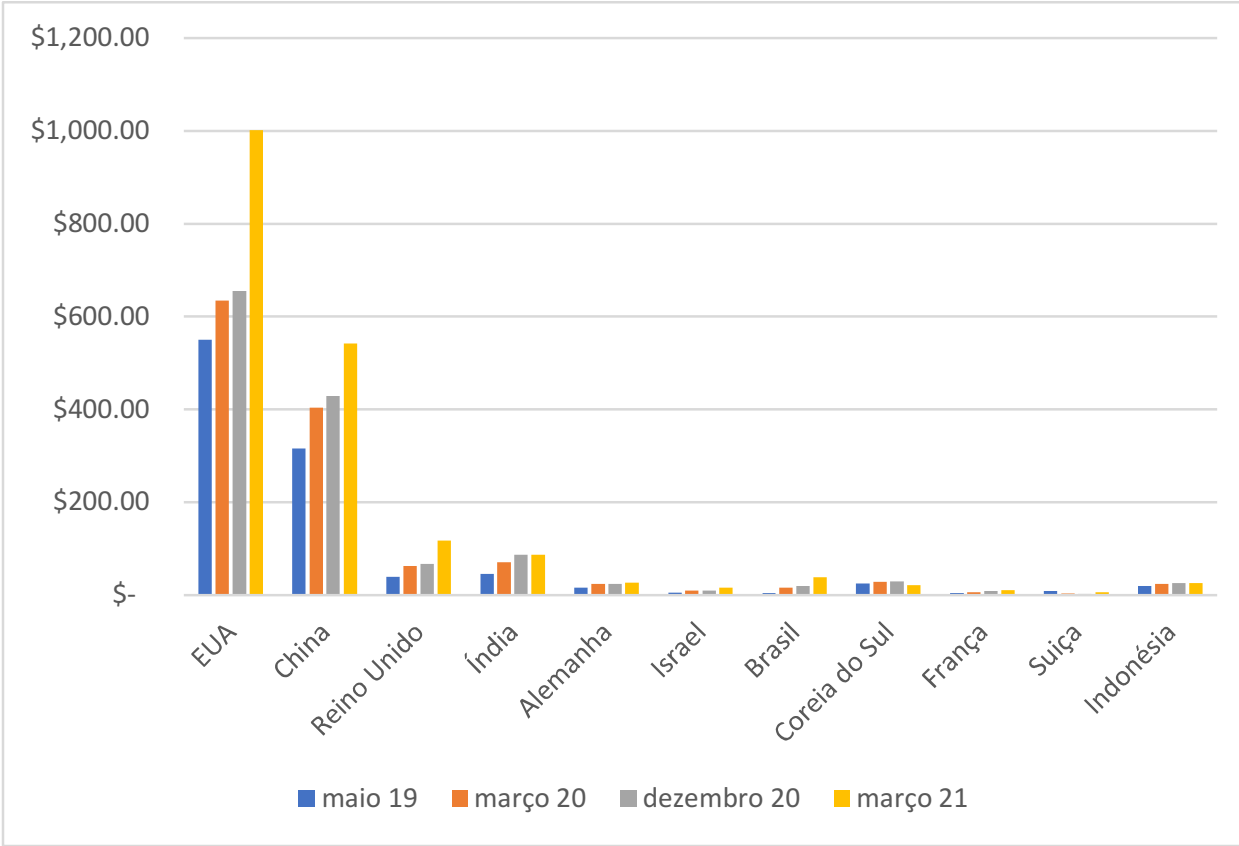

Fonte: Autor, 2021.

Assim, é possível verificar que mesmo com o surgimento de novas empresas unicórnios em outros países, os EUA e a China continuam dominando esse fenômeno. Juntos, no levantamento de março de 2021, em quantidade possuem $72,6 \%$ das empresas unicórnios e $77 \%$ na soma dos valuation.

As empresas unicórnios globais, desde o mapeamento de 04 de março de 2020, estão divididas em 16 categorias, segmentadas por suas áreas de atuações. $\mathrm{Na}$ figura abaixo, é possível visualizar a quantidade de unicórnios por categoria no último mapeamento da $C B$ Insight. 
Figura 10 - Empresas Unicórnios Globais por Áreas de Atuação

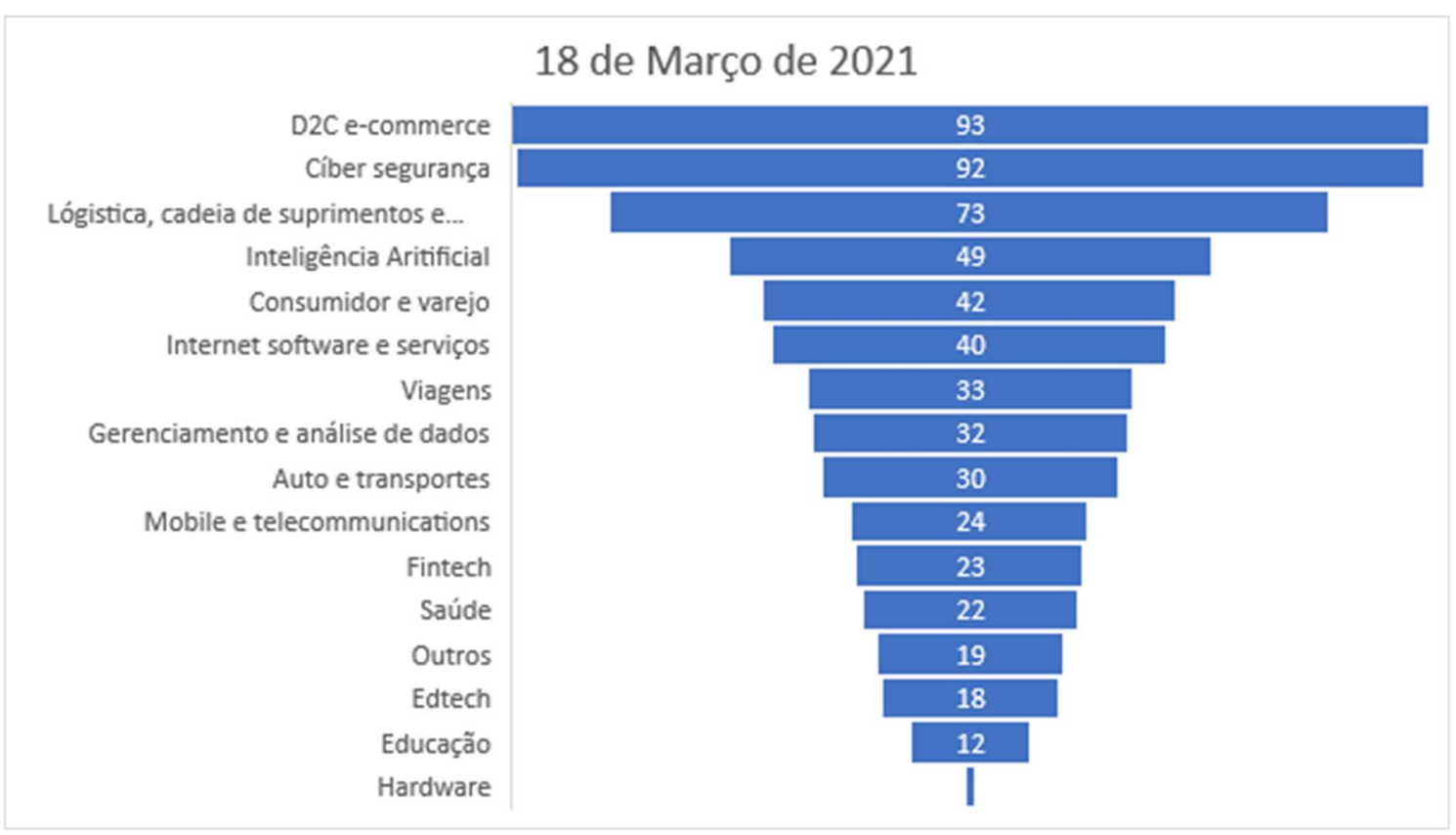

Fonte: Autor, 2021.

Para ser uma empresa unicórnio é necessário permanecer nos critérios do título, quais sejam: valuation de, no mínimo, um bilhão de dólares e não realizar IPO (oferta pública inicial). Portanto, a lista de unicórnio da $C B$ Insight varia frequentemente, assim, ao analisar-se a segmentação dessas empresas, pode-se perceber que é uma informação momentânea. Não foi possível identificar uma relação concreta na segmentação e a evolução dos unicórnios nos quatro momentos analisados.

Outro destaque é a baixa quantidade de fintechs na lista, em março de 2021. Nos períodos anteriores, março e dezembro de 2020, tiveram, respectivamente, 60 e 75 fintechs. Desse modo, percebeu-se que, apesar da queda na quantidade desse segmento, houve um aumento nos últimos anos dos IPO dessa mesma área. Só nos EUA em 2020, 15 fintechs fizeram sua oferta pública inicial. No Brasil, dos 3 "IPOgrifos", termo utilizado pela plataforma Distrito para representar os unicórnios de capital aberto, 2 são fintechs. 


\subsection{Dados Brasileiros}

Desde o surgimento do primeiro unicórnio brasileiro, janeiro de 2018, o Brasil vem se destacando na evolução desse fenômeno. Na Figura 11 pode-se perceber que em maio de 2019, foi identificado apenas 2 unicórnios que valiam, juntos, \$ 5 bilhões de dólares. Já em março de 2021, atualização mais recente, mapeou-se 11 unicórnios com um valor total de $\$ 38,45$ bilhões de dólares. No período mapeado, o Brasil, teve um crescimento de $550 \%$, em relação a quantidade de empresas unicórnios, e um crescimento de $769 \%$ na soma dos valuation.

Figura 11 - Evolução do fenômeno das empresas unicórnios do Brasil.

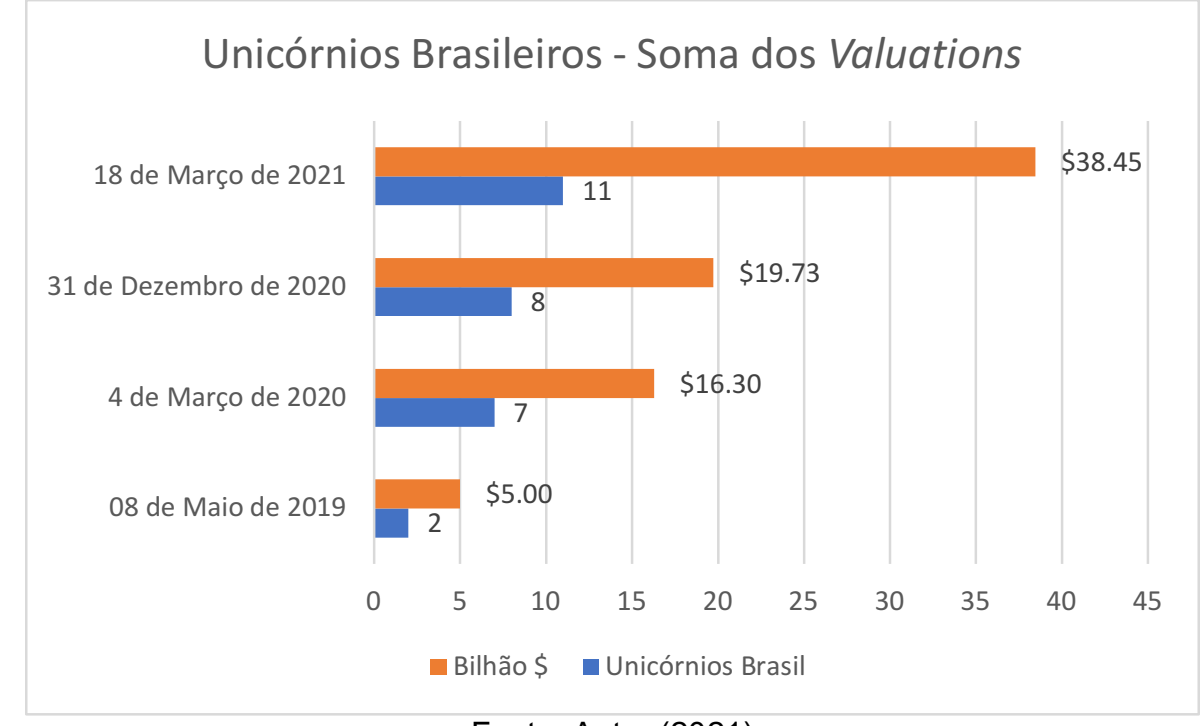

Fonte: Autor (2021)

Pelo mapeamento da CB Insight, foi possível identificar os 11 unicórnios brasileiros da atualidade, referentes a data de 18 de março de 2021. Assim, realizouse uma compilação das informações dessas empresas para descrever a ocorrência dos unicórnios. 
Figura 12 - As 11 Empresas unicórnios brasileiras

\begin{tabular}{|c|c|c|c|c|c|c|c|}
\hline Unicórnio & Fundação & Dia Unicórnio & Segmento & Sede & Funcionários * & Captação & Valuation (\$B) \\
\hline Movile & 1998 & Novembro 2018 & Celular e telecomunicações & Campinas, $\mathrm{SP}$ & 6286 & US\$175M & $\$ 1.00$ \\
\hline VTEX & 1999 & Setembro 2020 & D2C e-commerce & São Paulo, SP & 1312 & US\$365M & $\$ 1.70$ \\
\hline MadeiraMadeira & 2009 & Janeiro 2021 & D2C e-commerce & Curitiba, PR & 1280 & US\$335,4M & $\$ 1.00$ \\
\hline Wildlife Studios & 2011 & Dezembro 2019 & Outros & São Paulo, SP & 928 & US\$180M & $\$ 3.00$ \\
\hline iFood & 2011 & Novembro 2018 & Lógistica, cadeia de suprimentos e delivery & São Paulo, SP & 5928 & US\$591,8M & $\$ 1.00$ \\
\hline Creditas & 2012 & Dezembro 2020 & Fintech & São Paulo, SP & 2184 & US\$568,9M & $\$ 1.75$ \\
\hline EBANX & 2012 & Outubro 2019 & Fintech & Curitiba, PR & 778 & US\$30M & $\$ 1.00$ \\
\hline Nubank & 2013 & Março 2018 & Fintech & São Paulo, SP & 3911 & US\$1,42B & $\$ 25.00$ \\
\hline Loggi & 2013 & Junho 2019 & Lógistica, cadeia de suprimentos e delivery & São Paulo, SP & 2443 & US\$295M & $\$ 1.00$ \\
\hline QuintoAndar & 2013 & Setembro 2019 & D2C e-commerce & São Paulo, SP & 1911 & US\$335,4M & $\$ 1.00$ \\
\hline Loft & 2018 & Janeiro 2020 & D2C e-commerce & São Paulo, SP & 1093 & US\$275M & $\$ 1.00$ \\
\hline
\end{tabular}

Fonte: Autor, 2021.

A Loft, startup imobiliária, levou cerca de 16 meses, desde o início de suas operações, para atingir o patamar de unicórnio, em janeiro de 2020, adquirindo o título de unicórnio mais rápido do Brasil.

Os unicórnios brasileiros estão divididos em 5 segmentos. Em D2C ecommerce, existem 4 unicórnios, seguidos por 3 em fintech, 2 em logística, cadeia de suprimentos e delivery, 1 em celular e telecomunicações e, para finalizar, a Wildlife Studios, empresa de jogos, na categoria outros.

Um fator de destaque dos 11 unicórnios brasileiros é que 8 deles estão localizados na cidade de São Paulo, 1 na cidade de Campinas, no Estado de São Paulo, e outros 2 em Curitiba, no Estado do Paraná.

Juntos, os unicórnios brasileiros, possuem 28.054 colaboradores. Tais valores são referentes aos funcionários autodeclarados, que foram encontrados no perfil de cada empresa na plataforma do Linkedln no dia 27 de abril de 2021. A empresa com a maior quantidade de funcionários, 6286, é a Movile, apesar da categoria de celular e telecomunicações, atualmente é uma holding que dentre os investimentos realizados encontra-se o lfood.

As 11 empresas receberam um aporte total, de 4,571 bilhões de dólares de investimentos. E juntas, possuem um valuation de 38,45 bilhões de dólares. $O$ Nubank, fintech pioneira em serviços bancários gratuitos, em 28 de janeiro de 2021, segundo o próprio site do Nubank, realizou uma nova rodada de investimento e captou 400 milhões de dólares (NUBANK, 2021). Com isso, a empresa soma um aporte total de 1,42 bilhões. Consequentemente, a empresa que antes era avaliada em 10 bilhões de dólares no último mapeamento de 31 de dezembro de 2020, passou a ser avaliada em 25 bilhões de dólares e se manteve na posição de o unicórnio mais valioso do Brasil. 


\subsection{Hipóteses Bock e Hackober}

Bock e Hackober (2020) levantaram quatro hipóteses que favoreciam o surgimento dos unicórnios, porém, apenas três delas tiveram uma influência determinante nesse processo. As hipóteses sugeridas, e se foram descartadas ou comprovadas pelos autores, foram:

1. Reputação dos investidores, descartado;

2. Investimentos de CVC, validado;

3. Cluster econômicos ou de inovações, validado;

4. Crescimento inorgânico, validado.

Em vista disso, o estudo utilizou as hipóteses que tiveram alguma relação positiva com o surgimento de novos unicórnios para verificar se o fenômeno brasileiro se encaixa na teoria levantada pelos autores.

Figura 13 - Check das Empresas unicórnios vs. hipóteses de Bock e Hackober (2020)

\begin{tabular}{|l|c|c|c|}
\hline \multicolumn{1}{|c}{ Empresa } & $\begin{array}{c}\text { Cluster } \\
\text { Inovador }\end{array}$ & CVC & $\begin{array}{c}\text { Crescimento } \\
\text { Inorgânico }\end{array}$ \\
\hline Nubank & $\mathrm{X}$ & - & - \\
\hline Wildlife Studios & $\mathrm{X}$ & - & - \\
\hline Creditas & $\mathrm{X}$ & - & $\mathrm{X}$ \\
\hline VTEX & $\mathrm{X}$ & - & $\mathrm{X}$ \\
\hline Movile & - & - & $\mathrm{X}$ \\
\hline iFood & $\mathrm{X}$ & - & - \\
\hline Loggi & $\mathrm{X}$ & $\mathrm{X}$ & - \\
\hline QuintoAndar & $\mathrm{X}$ & - & - \\
\hline EBANX & - & - & - \\
\hline Loft & $\mathrm{X}$ & - & - \\
\hline MadeiraMadeira & - & - & $\mathrm{X}$ \\
\hline
\end{tabular}

Fonte: Autor, 2021.

Na Figura 13 “X” representa afirmação e, “-“, negação. Assim, é possível identificar quais empresas se encaixam nas hipóteses levantadas por Bock e Hackober. 
Das 11 empresas analisadas, apenas o EBANX não se encaixa em nenhuma das hipóteses. A fintech, que oferece soluções de pagamentos, é de Curitiba no Estado do Paraná, portando não se encontra no agrupamento de inovação da cidade de São Paulo. Segundo o banco de dados da CB Insight, a empresa possuiu dois investidores, sendo um venture capital e o outro private equity. Nos últimos dois anos, a empresa realizou dois M\&A. Apesar disso, não foram encontradas informações relacionando essas fusões e aquisições com rodadas de investimentos baseadas em estratégias de crescimento inorgânico.

\subsubsection{Cluster Inovador}

Após a realização de um check, para verificar quais das onze empresas brasileiras tiveram, parte das hipóteses sugeridas por Bock e Hackober. Assim, através dos dados de cada empresa foi possível encontrar fatores semelhantes que se encaixavam nas teorias dos autores.

Ao analisar clusters inovadores ou econômicos no Brasil, percebeu-se que a cidade de São Paulo é a região do Brasil que mais se aproxima de um agrupamento de inovação, utilizando os parâmetros definidos por Bock e Hackober (2020). Dos 11 unicórnios brasileiros, 9 estão localizados no Estado de São Paulo, 8 na capital e 1 em Campinas (Moville).

Segundo a São Paulo Tech, levantamento produzido pela empresa de inovação aberta Distrito em parceria com a ABStartups e a KPMG, as startups do estado de São Paulo, em 2019, receberam US\$ 2,484 bilhões de investimentos, isso representa $83 \%$ de todo o volume aplicado em startups. Esse valor investido chega a ser superior a países da América Latina como México, Colômbia, Chile, Argentina. Desde 2018, foram realizados mais de US $\$ 4$ bilhões de investimentos no Estado.

Há vários fatores para explicar o motivo pelo qual o Estado de São Paulo acumula tantos unicórnios, como se passa a demonstrar.

O Estado de São Paulo possui, no total, 2677 startups, e 70,8\% delas estão concentradas na capital. A Região Metropolitana de São Paulo é composta por 37 municípios e possuem $23,6 \%$ da população, 49 milhões de consumidores potenciais, e 33,3\% da renda total do Brasil (DOLABELA, 2020). 
Além da questão econômica, o Estado de São Paulo, concentra 4 das 30 melhores universidades da América Latina: USP, UNICAMP, UNESP e UNIFESP (DISTRITO, 2019). Na capital, é possível encontrar campus de 3 delas, USP, UNESP e UNIFESP.

Ademais, segundo o estudo do MCTIC (Ministério da Ciência Tecnologia e Inovações), Aprotec e CNPq (Conselho Nacional de Desenvolvimento Científico e Tecnológico) no estado existem 57 incubadoras ativas. O relatório da Distrito destacou a atuação de 5 delas, 3 localizadas na cidade de São Paulo. Os principais hubs de inovação do país, também estão localizados na capital, dentre eles estão Cubo, INNOVATORS - Brazil - Silicon Valley, Campus Google e Inovabra (DISTRITO,2019).

Como se não bastasse, o governo do Estado de São Paulo possui a INVESTSP, Agência Paulista de Promoção de Investimentos e Competitividade, diretamente ligada a Secretaria Estadual de Desenvolvimento Econômico do Estado de São Paulo. Em 2017, o governo paulista investiu mais de $\mathrm{R} \$ 10$ bilhões em pesquisa e desenvolvimento. Isso representa $70 \%$ do total investido pelos estados do Brasil. Na plataforma da INVESTSP é possível encontrar 59 institutos de pesquisa, 9 centros de inovação tecnológica e 22 parques tecnológicos instalados no Estado.

Segundo a Forbes (2019), a cidade de São Paulo é referência quando se trata de inovação na América Latina. Ela possui um ecossistema de inovação que evolui rapidamente. Assim a as complexidades da megalópole oferecem um leque de ofertas para empreendedores e investidores usá-las e inovarem, juntamente com uma grande quantidade de consumidores em potencial. Além dos fatores citados acima, é a base latino-americana de 65\% das empresas da Fortune 500 - lista anual da revista "Fortune" com as 500 maiores corporações norte americanas, tornando-se em um centro de tomada de decisões. A grande quantidade de empresas na capital, favorece startups, da área de tecnologia, para iniciarem suas operações e, futuramente, receberem investimentos, ou até mesmo, realizarem fusões e aquisições para auxiliarem nas operações dessas empresas (MARI, 2019).

Ainda, para Michel Porcino, gerente da SP Negócios, os grandes problemas urbanos encontrados em São Paulo acabam se tornando um enorme leque de oportunidades a serem exploradas pelos empreendedores. Para ele, se o empreendedor for capaz de criar soluções eficientes para a cidade de São Paulo, como uma startup de mobilidade urbana, conseguirá replicá-las em qualquer outra cidade (FORBES, 2019). 


\subsubsection{Corporate Venture Capital - CVC}

Em seguida, importante analisar o elemento dos investimentos por CVC sugerida por Bock e Hackober. Segundo o banco de dados da CB Insight, os 11 unicórnios brasileiros receberam investimentos de 24 empresas. Dentre elas estão 15 VC, 6 PE, 1 banco de investimento, 1 holding no ramo de comidas e bebidas, e 1 CVC. As definições dos tipos de investimento dessas empresas foram obtidas através do perfil, de cada uma, na plataforma Crunchbase.

O CVC responsável pelo investimento é o Qualcomm Ventures, que é o braço de investimento da Qualcomm Incorporated. No site da Qualcomm Ventures, em seu portfólio ativo eles possuem mais de 150 empresas. Dentre elas estão a 99, primeiro unicórnio brasileira que já saiu da lista, a Waze, aplicativo de navegação de GPS subsidiária da Google, e a atual unicórnio Loggi, startup de tecnologia focada em logística. Segundo o CVC Report de 2020, da CB Insight, a Qualcomm Ventures está entre os $10 \mathrm{CVC}$ mais ativos do mundo.

Segundo dados da CB Inisght, globalmente, atualmente um terço dos investimentos em startups tem alguma corporate envolvida. Em 2019, 984 CVC participaram de 3416 negócios, $25 \%$ de todo o valor investido em startups no mundo, com um total de US $\$ 57,1$ bilhões distribuídos. Já em 2020, apesar da queda de $5 \%$ no número de negócios, 979 CVC participaram de 3359 investimentos, houve um aumento de $24 \%$ no capital investido, chegando aos US $\$ 73,1$ bilhões. Além disso, rodadas de investimentos acima de US $\$ 100$ milhões com a participação de CVC atingiu o marco recorde de 182 em 2020, um aumento de 48\% em relação a 2019 (CB INSIGHT, 2021).

Ainda com os dados da CB Insight, a maior parte dos investimentos CVC ocorrem no continente no continente asiático, $38 \%$, no norte americano, $38 \%$ e no europeu, $19 \%$. Os outros 3\% estão distribuídos na América do Sul, África e Oceania. Para se ter uma ideia do tamanho do movimento na Ásia, só na China 90\% das empresas unicórnios possuem, no mínimo, um investidor corporate.

Apesar do investimento por CVC estar presente em boa parte das empresas unicórnios globais, verifica-se que, no Brasil, os investimentos por CVC ainda é muito incipiente. Uma pesquisa realizada pelo boostLAB e pela ACE Cortex, mostrou que $62 \%$ dos programas de investimentos corporate brasileiros têm menos 
de 2 anos (BRIGATTO, 2021). Em vista disso, segundo dados do Distrito Dataminer, o CVC representa $10 \%$ dos investimentos realizados, US\$300 milhões. Sendo que US\$ 200 milhões foram investidos em estágios iniciais, através de rodadas anjo, préseed e seed, cenário oposto ao que acontece no restante do mundo, tendo em vista que os investimentos são realizados em startups que já estão em uma fase mais avançada de crescimento (CRUZ, c2021).

Deste modo, apesar do crescente número de projetos de corporate venture capital no Brasil, ainda há bastante espaço para se desenvolver.

\subsubsection{Inorganic Growth - crescimento inorgânico}

Para Bock e Hackober (2020) as estratégias de crescimentos inorgânicos, instrumentalizado pelas transações de M\&A, também representam um fator de tração dos unicórnios.

Isso porque os M\&As refletem significativas alavancas para o aumento de lucro e geração de valor de ambas as partes envolvidas: de um lado, para o investidor, corresponde a um rápido acesso a novos mercados e atividades, e, para a investida, um mecanismo alternativo de captação de investimento.

No entanto, analisando os 11 unicórnios brasileiros para identificação de quais captaram recursos para executar planos de M\&A, é possível perceber que apenas 4 deles realizaram rodadas de investimentos focadas em estratégias de fusões e aquisições.

A Creditas, fintech de créditos que opera em soluções para o consumidor, utilizou-se do seu plano de crescimento inorgânico para captar, em sua rodada de investimento de Série D, US\$231 milhões do SoftBank (ESTADÃO CONTEÚDO, 2019). Com esse valor a Creditas realizou a aquisição da empresa Creditoo, startup de crédito consignado para funcionários de empresas privadas. Posteriormente, na rodada de investimento de Série E liderada pela LGT Lightstone, a fintech conseguiu realizar uma captação de $\mathrm{R} \$ 255$ milhões, e assim atingiu o status de empresa unicórnio. O último aporte também fez parte do plano de M\&A dela, após o investimento adquirido, a empresa realizou a compra da Bcredi, plataforma digital de crédito imobiliário (NERY, 2021). 
Nesse contexto, a VTEX, empresa que desenvolve sistemas para comércio eletrônico, desde sua fundação, em 1999, realizou a compra de 10 empresas. No final de 2019, realizaram uma rodada de investimento, na qual apresentou estratégias de M\&A para conseguirem o aporte de US\$140 milhões do SoftBank. Após a captação, a VTEX, realizou a compra das empresas Biggy e dLieve. A rodada de investimento que deu o status de unicórnio para empresa captou US $\$ 225$ milhões, liderado pelo SoftBank (OLHAR DIGITAL, 2020). O investimento foi utilizado para a expansão da startup nos Estados Unidos e na Europa, expansão através de fusões e aquisições (MOURA, 2020).

Verifica-se que a Movile, na sua essência, já possui um modelo de negócio focado ao M\&A. Desse modo, qualquer aporte realizado na empresa seguirá uma estratégia de fusões e aquisições. A Movile desde sua fundação, em 1999, além de terem investidos em outras empresas, já realizou 8 M\&As (MOVILE, c2021). Segundo a CB Insight, a empresa já recebeu um total de US $\$ 175$ milhões.

Ainda, a MadeiraMadeira, especializada em venda on-line de material de construção e móveis, entrou para a lista de unicórnios com um aporte de US $\$ 190$ milhões, através de uma rodada de investimento de Série E coliderada pelo SoftBank e pela Dynamo. Com essa captação, a empresa irá focar em sua expansão pelo país, utilizando-se de estratégias de crescimento inorgânico (ESTADÃO CONTEÚDO, 2021).

Apesar de poucos unicórnios estarem ligados às transações de M\&As, verifica-se que o cenário vem se alterando. Apenas a título exemplificativo, $60 \%$ dos M\&As, da última década, foram realizados nos anos de 2019 e 2020. 
Figura 14 - Evolução de Transações de M\&A

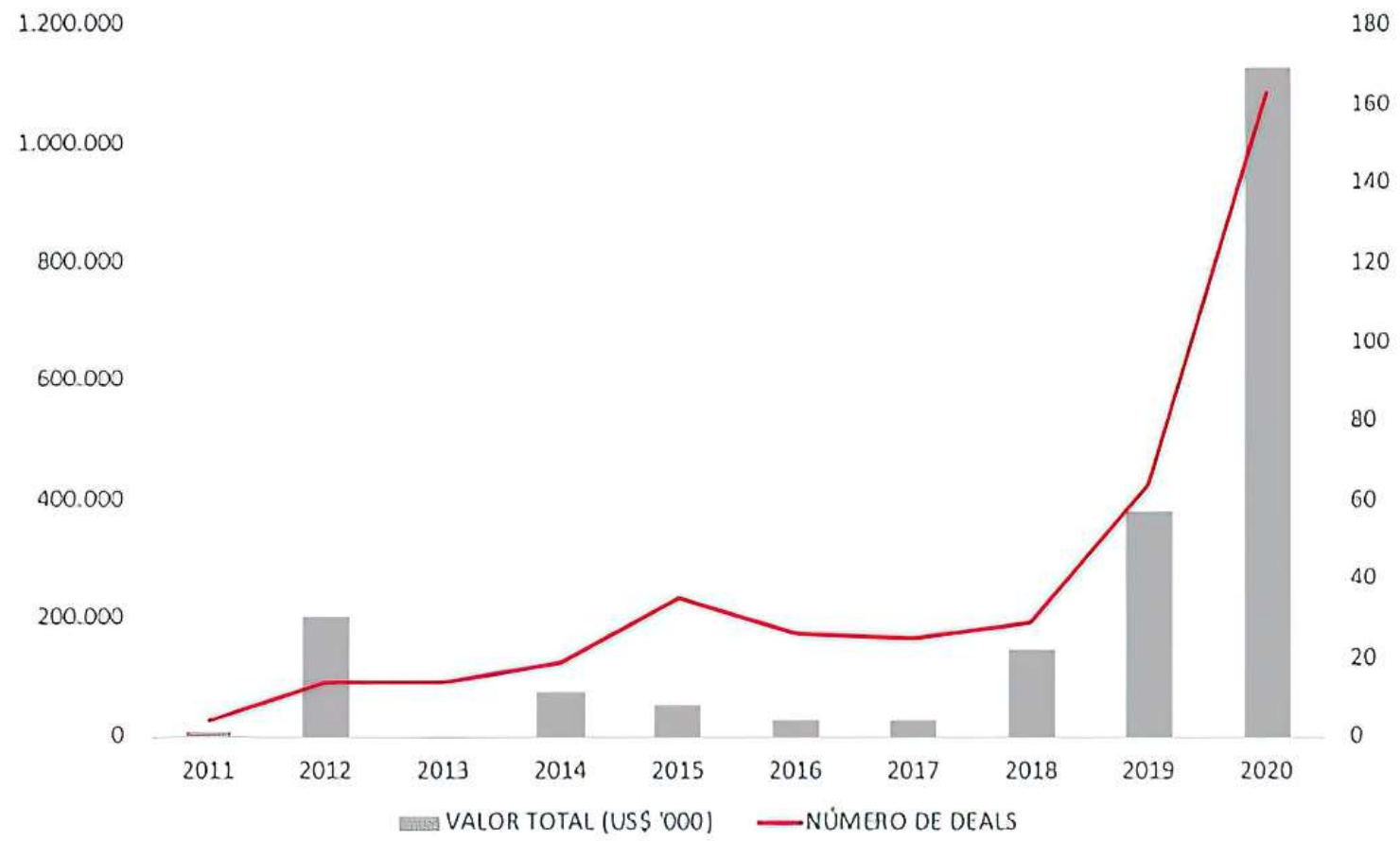

Fonte: Inside Venture Capital da Distrito (2021).

A Figura 14 mostra que o valor total de investimento e o número de $M \& A$ possui uma relação direta. Por todo o exposto, observa-se que a realização de M\&A pelas startups vêm crescendo exponencialmente nos últimos anos, o que favorece estratégias de crescimento inorgânico. 


\section{CONSIDERAÇÕES FINAIS}

O presente estudo teve como objetivo principal realizar um estudo descritivo do surgimento das empresas unicórnios do Brasil. Assim, utilizou-se de um banco de dados global, produzido pela empresa CB Insight, para identificar as empresas unicórnios da atualidade. Posteriormente, apresentou-se dados que mapeavam o fenômeno no mundo e no Brasil. E, para finalizar, buscou-se levantar uma semelhança entre o surgimento dos unicórnios brasileiros e as hipóteses de favorecimento do surgimento de unicórnios anunciadas por Bock e Hackober (2020), levando-se em conta dados qualitativos.

De início, apresentou-se referencial teórico sobre empreendedorismo, inovação, startups, venture capital, private equity e empresas unicórnios. Com os tópicos abordados no referencial teórico pretendia-se apresentar uma contextualização histórica, além de expor conceitos determinantes para a compreensão do fenômeno dos unicórnios.

Em sequência, realizou-se a contextualização dos unicórnios globais e dos brasileiros, através da exibição das informações obtidas pela análise do banco de dados da $\mathrm{CB}$ Insight em quatro períodos distintos. Assim foi possível descrever a evolução do fenômeno em quantidade, a soma dos valuations, a divisão por área de atuação e os 11 unicórnios do Brasil. Identificou-se que o fenômeno do surgimento das empresas unicórnios continua sendo de dominância norte americana e chinesa. EUA e China possuem $72,6 \%$, em quantidade, e $77 \%$, na soma dos valores, dos unicórnios. Ao mesmo tempo, o fenômeno no Brasil está se desenvolvendo e demonstra enorme potencial de crescimento. Logo, o presente estudo mostra-se essencial e relevante para o tema proposto.

Já o fenômeno no Brasil, nesses dois anos de acompanhamento, teve um crescimento de $550 \%$, em relação a quantidade, e $769 \%$, em relação a soma dos valuation, das empresas unicórnios. Atualmente, os 11 unicórnios brasileiros somam um valor de mercado de US $\$ 38,45$ bilhões e receberam um aporte de US $\$ 4,571$ bilhões.

Ao analisar as hipóteses de Bock e Hackober (2020) com os 11 unicórnios brasileiras, percebeu-se que apenas 1 empresa não se encaixa em nenhuma das hipóteses, o que comprova a magnitude dos estudos de Bock e Hackober. Na hipótese de cluster de inovação, foram apresentados dados que 
mostram que o Estado de São Paulo oferece condições especiais para empreender. Nessa toada, a cidade de São Paulo é o maior, e talvez o único, agrupamento de inovação brasileiro. Assim, pôde-se concluir que a maior cidade brasileira oferece condições únicas que variam desde o incentivo a inovação, potenciais consumidores e investimentos, além de um campo fértil de diversos problemas para solucionar, ou seja, as chances de se tornar uma empresa unicórnio na cidade de São Paulo é superior a qualquer outra cidade do Brasil, tanto que dos 11 unicórnios estudados, 8 surgiram na cidade em questão.

Por outro lado, na segunda hipótese que trata dos investimentos de CVC nas empresas unicórnios, apenas 1 empresa se encaixou nesse perfil. Concluiu-se, que os investimentos de CVC no Brasil ainda são incipientes para elaborar alguma relação com o surgimento dos unicórnios. Portanto, pela falta de dados e informações, recomenda-se aguardar o amadurecimento desse tipo de investimento no Brasil, que se mostra promissor, para a realização de pesquisas futuras.

A terceira hipótese, crescimento inorgânico, identificou 4 empresas que possuem essa estratégia e atingiram o clube dos unicórnios. Percebeu-se que esse tipo de estratégia atraí rodadas de investimentos em valores consideráveis, e os investidores participantes, geralmente, são grandes empresas sólidas no mercado internacional. Dessas 4 empresas, 3 receberam aporte de mais de US\$140 milhões cada, todas da corporação japonesa SoftBank.

Em suma, devido a importância das empresas unicórnios na microeconomia, no desenvolvimento de tecnologias inovadoras e por ser um fenômeno constante, seu surgimento, é um estudo que possui continuidade. Em relação aos unicórnios globais é interessante verificar se o surgimento dessas empresas está ocorrendo de forma mais distribuída, com participações maiores de países além dos EUA e da China. Já os unicórnios brasileiros possuem dados promissores para os próximos anos, principalmente com o possível amadurecimento dos investimentos de CVC e a consolidação de estratégias de crescimento inorgânico. Assim, esse estudo recomenda pesquisas futuras para continuar o mapeamento aqui iniciado e a reavaliação das hipóteses de Bock e Hackober com informações e dados mais sólidos. 


\section{REFERÊNCIAS}

ABVCAP. Consolidação de Dados da Indústria de Private Equity e Venture Capital no Brasil, 2014. Disponível em: http://www.abvcap.com.br/Download/ Estudos/3233.pdf. Acesso em: 19 dez. 2020.

ACHLEITNER, Ann-Kritin; BRAUN, Reiner Braun; LUTZ, EVA; TAPPEINER, Florian. Private equity group reputation andfinancing structures in German leveraged buyouts. Journal of Business Economics, v. 88, n. 3, p. 363-392. Disponível em: https://econpapers.repec.org/article/sprjbecon/v_3a88_3ay_3a2018_3ai_3a3_3ad_3 a10.1007_5fs11573-017-0866-4.htm. Acesso em: 18 abr. 2021.

BLANK, Steve. Why the lean start-up changes everything. Harvard Business Review, v. 91, n. 5, p. 63-72, 2013. Disponível em: https://hbr.org/2013/05/why-thelean-start-up-changes-everything. Acesso em: 19 dez.2020.

Press, 2012.

; DORF, Bob. The startup owner's manual. 1.Ed. Pescadero: K \& S Ranch

BLOCK, Joern Hendrich; COLOMBO, Massimo G.; CUMMING, Douglas; VISMARA, Silvio. New players in entrepreneurial finance and why they are there. Small Business Economics, 50, p. 239-250, 2018. Disponível em: https://www.researchgate.net/publication/312510379_New_players_in_entrepreneuri al_finance_and_why_they_are_there. Acesso em: 21 abr. 2021.

BOCK, Carolin; HACKOBER, Christian. Unicorns - what drives multibillion-dollar valuations? Business Research, 13, p. 949-984, 2020. Disponível em: https://link.springer.com/article/10.1007/s40685-020-00120-2. Acesso em: 20 abr. 2021.

BORNELI, Júnior. Darwin e a Seleção Natural das Empresas, 2019. Disponível em: https://www.startse.com/noticia/mercado/darwin-e-a-selecao-natural-das-empresasmentoria. Acesso em: 03 fev. 2021.

BRIGATTO, Gustavo. Maior parte dos corporate ventures no Brasil tem menos de 2 anos e está em fases iniciais de desenvolvimento, 2021. Disponível em: https://startups.com.br/noticias/maior-parte-dos-corporate-ventures-no-brasil-temmenos-de-2-anos-e-esta-em-fases-iniciais-de-desenvolvimento/. Acesso em: 05 maio 2021

BROWN, Keith C.; WILES, Ken. In Search of Unicorns: Private IPOs and the Changing Markets for Private Equity Investments and Corporate Control. Journal of Applied Corporate Finance, 27, p. 34-48, 2015. Disponível em: https://www.researchgate.net/publication/318420591_In_Search_of_Unicorns_Privat e_IPOs_and_the_Changing_Markets_for_Private_Equity_Investments_and_Corpora te_Control. Acesso em: 17 abr.2021.

BRUYAT, C.; JULIEN, P. A. Defining the field of research in entrepreneurship. Journal of Business Venturing, v. 16, n. 2, p. 165-180, mar. 2001. 
CARVALHO, A. G.; RIBEIRO, L. L.; FURTADO, C. V. Tipos de investimento de capital de risco. In: CRIATEC. Desmistificando o capital de risco, 2009. 36p. Disponível em: http://www.fundocriatec.com.br/Recursos/Paginas/Arquivos/cartilhacriatec.pdf. Acesso em: 19 dez. 2020.

CASTILLA, Emilio J. Networks of venture capital firms in Silicon Valley. International Journal of Technology Management, 25, p. 113-135, 2003. Disponível em:

https://www.researchgate.net/publication/228392719_Networks_of_Venture_Capital_ Firms_in_Silicon_Valley. Acesso em: 21 abr. 2021.

CB INSIGHTS. The Global 2020 Global CVC Report, 2020. Disponível em: https://www.cbinsights.com/research/report/corporate-venture-capital-trends-2020/.

Acesso em: 05 abr.2021.

. The Complete List Of Unicorn Companies, 2019. Disponível em: https://www.cbinsights.com/research-unicorn-companies/. Acesso em: 22 maio 2019.

. The Complete List Of Unicorn Companies, 2020. Disponível em: https://www.cbinsights.com/research-unicorn-companies/. Acessado em: 10/03/2020.

The Complete List Of Unicorn Companies, 2021. Disponível em: https://www.cbinsights.com/research-unicorn-companies/. Acesso em: 25 mar. 2021.

CHEMMANUR, Thomas J.; LOUTSKINA, Elena; TIAN, Xuan. Corporate Venture Capital, Value Creation, and Innovation. Review of Financial Studies, v. 27, v. 8, p. 2434-2473, 2014. Disponível em: https://academic.oup.com/rfs/articleabstract/27/8/2434/1583161. Acesso em: 18 abr. 2021.

CHESBROUGH, Henry William. Designing Corporate Ventures in the Shadow of Private Venture Capital. California Management Review, v. 42, n. 3, p. 31-49, 2000. Disponível em: https://www.semanticscholar.org/paper/Designing-CorporateVentures-in-the-Shadow-of-

Chesbrough/665bd4c8bd24c3fea98094c81d02271c1862cc27. Acesso em: 18 abr. 2021.

CRUZ, Ana Beatriz; MEDEIROS, Marcelo. O cenário de CVC no Brasil, 2021. Disponível em: https://acestartups.com.br/cvc-no-brasil/. Acessado em: 0505/2021. de Teresa Cristina Felix de Souza. 7. ed. Porto Alegre: Bookman, 2009.

DISTRITO. Corrida dos unicórnios, 2021. Disponível em: https://conteudo.distrito.me/unicornios. Acesso em: 26 abr. 2021.

Inside Venture Capital, 2021. Disponível em: https://conteudo.distrito.me/dataminer-inside-venture-capital-brasil. Acesso em: 26 abr. 2021.

São Paulo Tech Report, 2020. Disponível em: https://conteudo.distrito.me/dataminer-sao-paulo. Acesso em: 26 abr. 2021. 
DOLABELA, Fernando. Oficina do empreendedor. Rio de Janeiro: Sextante, 2008. ECONOMIA, R7. Grande São Paulo concentra $23 \%$ da população e $33 \%$ da renda nacional, 2020. Disponível em: https://noticias.r7.com/economia/grande-sao-pauloconcentra-23-da-populacao-e-33-da-renda-nacional-25062020. Acesso em: 05 maio 2021.

ESTADÃO CONTEÚDO. MadeiraMadeira levanta aporte de US\$190 mi e se torna - $1^{\circ}$ unicórnio brasileiro, 2021. Disponível em: https://economia.uol.com.br/noticias/estadao-conteudo/2021/01/07/madeiramadeiralevanta-aporte-de-us-190-mi-e-se-torna-o-14-unicornio-brasileiro.htm. Acesso em: 05 maio 2021.

Disponível em: https://www.infomoney.com.br/minhas-financas/creditas-comprastartup-de-credito-consignado-creditoo-2/. Acesso em: 05 maio 2021.

FACHIN, O. Fundamentos de metodologia. 3. ed. São Paulo: Atlas, 2001.

FILLION, L. J. Empreendedorismo: empreendedorismo e proprietários-gerentes de pequenos negócios. São Paulo: Revista de Administração, v. 34, n. 2, p. 05-28, abr./jun. 1999.

FILLOUX, F. The Ripple Effects of Disruptive Models, 2014. Disponível em: https://mondaynote.com/the-ripple-effects-ofdisruptive-models-

b9eb56407f6b\#.6rlhy5fy7. Acesso em: 21 abr.2021.

GALLOWAY, Tera; MILLER, Douglas R.; SAHAYM, Arvin; ARTHURS, Jonathan D. Exploring the innovation strategies of young firms: Corporate venture capital and venture capital impact on alliance innovation strategy. Journal of Business Research, 71: p. 2016. 55-65, Disponível em: https://www.researchgate.net/publication/309561901_Exploring_the_innovation_strat egies_of_young_firms_Corporate_venture_capital_and_venture_capital_impact_on_ alliance_innovation_strategy. Acesso em: 21 abr.2021.

GIL, Antônio Carlos. Métodos e técnicas de pesquisa social. 6. ed. São Paulo: Atlas, 2008.

GILBERT, Brett Anitra; MCDOUGALL, Patricia P.; AUDRETSCH, David B. Clusters, knowledge spillovers and new venture performance: An empirical examination. Journal of Business Venturing, v. 23, n. 4, p. 405-422, 2008. Disponível em: https://www.sciencedirect.com/science/article/abs/pii/S0883902607000444. Acesso em: 18 abr. 2021.

GÖBEL, Celine. (2016). Start-Up Valuation Of Biotech Companies With Real Options A Case Study Of The Start-Up Organovo Holdings, Inc. HEC Paris, Paris. 2016. 
HAMMER, Benjamin; KNAUER, Alexander; PFLÜCKE, Magnus; SCHWETZLER, Bernhard. Inorganic growth strategies and the evolution of the private equity business model. Journal of Corporate Finance, v. 45, p. 31-63, 2017. Disponível em: https://papers.ssrn.com/sol3/papers.cfm?abstract_id=2338115. Acesso em: 25 abr. 2021.

HISRICH, R. D.; PETERS, M. P.; SHEPHERD, D. A. Empreendedorismo. Tradução HSU, David H. 2004. What Do Entrepreneurs Pay for Venture Capital Affiliation? The Journal of Finance, v. 59, n. 4, p. 1805-1844, 2004. Disponível em: https://onlinelibrary.wiley.com/doi/pdf/10.1111/j.1540-6261.2004.00680.x. Acesso em: 18 abr. 2021.

KAPLAN, Steven N.; LERNER, Josh. Venture Capital Data: Opportunities and Challenges. Harvard Business School Working Paper, n. 17-012, 2016. Disponível em: https://dash.harvard.edu/handle/1/27864358. Acesso em: 18 abr. 2021.

KAPLAN, S.N.; STROMBERG, P. 2000. How Do Venture Capitalists Choose Investments?: University of Chicago Working paper. Disponível em: https://citeseerx.ist.psu.edu/viewdoc/download?doi=10.1.1.201.5607\&rep=rep1\&type =pdf. Acesso em: 25 abr. 2021.

KASSICIEH, Suleiman K.; WALSH, Steven T.; CUMMINGS, John C.; MCWHORTER, Paul J.; ROMING, Alton D; Williams, W. David. Factors differentiating the commercialization of disruptive and sustaining technologies. IEEE Transactions on Engineering Management, v. 49, n. 4, p. 375-387, 2002. Disponível em: https://ieeexplore.ieee.org/document/1176866. Acesso em: 17 abr.2021.

KENNEY, Martin; ZYSMAN, John. Unicorns, Cheshire cats, and the new dilemmas of entrepreneurial finance. Venture Capital. An International Journal of Entrepreneurial Finance. v. 21, p. 35-50, 2019. Disponível em: https://kenney.faculty.ucdavis.edu/wp-content/uploads/sites/332/2018/11/UnicornsChesire-cats-and-new-dilemmas-of-entrepreneurial-finance-1.pdf. Acesso em: 21 abr. 2021.

KERAI, Anita. Role of Unicorn tag in gaining legitimacy and accessing funds. The Business and Management Review, v. 9(2), p. 119-127, 2017.

KESINGER, John W.; MARTIN, John D.; PETTY, J. William. Harvesting Value From Entrepreneurial Success. Journal of Applied Corporate Finance, 12, p. 81-93, 2000. Disponível em: https://www.researchgate.net/publication/46540892_Harvesting_Value_from_Entrepr eneurial_Success. Acesso em: 17 abr.2021.

KIRCHHOFF, B.; WALSH S. Entrepreneurship's role in commercialization of disruptive technologies. Berlin: Dunker und Humblot, p. 323-332, 2000.

KONDRATIEF, Nikolai D. The long waves in economic life. Ravenio Books, 2015. 
LEE, Aileen. Welcome To The Unicorn Club: Learning From Billion-Dollar Startups, 2013. Disponível em: https://techcrunch.com/2013/11/02/welcome-to-theunicorn-club/. Acesso em: 21 maio 2019.

LEE, Peggy M.; POLLOCK, Timothy G.; JIN, Kyuho. The contingent value of venture capitalist reputation. Strategic Organization, v. 9, n. 1, p. 33-69, 2011.

LEWIS, W. A. A Teoria do Desenvolvimento Econômico. Rio de Janeiro: Zahar Editores, 1960.

LUBIÁN F.J.; ESTEVES J. Managing to Deliver Value in a Digital World. In: Value in a Digital World. Palgrave Macmillan, Cham, 2017. Disponível em: https://doi.org/10.1007/978-3-319-51750-6 5. Acesso em: 18 abr. 2020.

MARI, Angelica. Por que São Paulo está pronta para inovar nos negócios, 2019. Disponível em: https://forbes.com.br/negocios/2019/04/por-que-sao-paulo-estapronta-para-inovar-nos-negocios/. Acesso em: 05 maio 2021.

MILANESI, Diana. Secondary Trading of Private Company Shares: New Opportunities and Challenges. SSRN Electronic Journal, 2012. Disponível em: https://papers.ssrn.com/sol3/papers.cfm?abstract_id=2630899. Acesso em: 17 abr.2021.

MOORE, Geoffrey A. Crossing the Chasm. Marketing and Selling Disruptive Product to Mainstream Customers. 3. ed. New York: Harper Business Press, 2014.

MOTA, Pedro Lula. Schumpeter: inovação, destruição criadora e desenvolvimento, 2016. Disponível em: https://terracoeconomico.com.br/schumpeter-inovacao-destruicao-criadora-edesenvolvimento/. Acesso em: 24/05/2019.

MOURA, Ruy. Vtex, de sistemas para o varejo, faz aquisições, 2020. Disponível em: https://fusoesaquisicoes.blogspot.com/2020/04/vtex-de-sistemas-para-o-varejofaz.html. Acesso em: 05 maio 2021.

NARAYANAN, V. K.; YANG, Yi; ZAHRA, Shaker A. Corporate venturing and value creation: A review and proposed framework. Research Policy, v. 38, p. 58-76, $2009 . \quad$ Disponível em: https://www.sciencedirect.com/science/article/abs/pii/S0048733308002060. Acesso em: 18 abr. 2021.

NERY, Carmen. Creditas foca em M\&A e mira imobiliário e auto, 2021. Disponível em: https://www.telesintese.com.br/creditas-foca-em-ma-e-mira-imobiliario-e-auto/. Acesso em: 07 maio 2021.

OCDE. Manual de Oslo: diretrizes para a coleta e interpretação de dados sobre inovação tecnológica. 3.ed. Publicada pela FINEP (Financiadora de Estudos e Projetos), 2006. 
OSBORNE, David; GAEBLER, Ted. Reinventando o governo: como o espírito empreendedor está transformando o setor público. 4. ed. Brasília: $\mathrm{MH}$ Comunicação, 1994.

PARK, Haemin Dennis; STEENSMA, Kevin. When does corporate venture capital add value for new ventures? Strategic Management Journal, 33. p. 1-22, 2012. Disponível

em: https://www.researchgate.net/publication/229895885_When_does_corporate_ventur e_capital_add_value_for_new_ventures. Acesso em: 21 abr.2021.

RAMALHO, C.; FURTADO, C. V.; LARA, R. A Indústria de Private Equity e Venture Capital. $2^{\circ}$ censo brasileiro. Agência Brasileira de Desenvolvimento Industrial, Centro de Gestão e Estudos Estratégicos. Brasília, Agência Brasileira de Desenvolvimento Industrial, 2011.

Redação Distrito. Corporate Venturing: panorama no Brasil e no mundo, 2020. Disponível em: https://distrito.me/corporate-venturing/. Acesso em: 05 maio 2021.

. Rodada de investimento: qual a chance de uma startup ir do Series A ao Series E? 2020. Disponível em: https://distrito.me/rodada-investimento-seed-seriesa/. Acesso em: 03 fev. 2021.

Redação Nubank. Nubank atrai US\$ 400 milhões em nova rodada de investimentos em 2021, 2021. Disponível em: https://blog.nubank.com.br/nubank400-milhoes-rodada-investimento-2021/. Acesso em: 02 maio 2021.

Redação Olhar Digital. Startup de e-commerce VTEX é o mais novo unicórnio brasileiro, 2020. Disponível em: https://olhardigital.com.br/2020/09/29/pro/startup-dee-commerce-vtex-e-o-mais-novo-unicornio-brasileiro/. Acesso em: 05 maio 2021.

RINDOVA, Violina P.; WILLIAMSON, Ian O.; PETKOVA, Antoaneta P.; SEVER, Joy Marie. Being goog or being known: an empirical examination of the dimension of the dimensions, antecedents, and consequences of organizational reputation. Academy of Management Journal. v.48, n.6, p. 1033-1049, 2005. Disponível em: https://www.semanticscholar.org/paper/Being-good-or-being-known\%3A-Anempirical-examination-RindovaWilliamson/10c169b103235401f0f5aa0663a8d0c621fd2ad2. Acesso em: 18 abr. 2021.

ROSSI, Matteo; FESTA, Giuseppe; SOLIMA, Ludovico; POPA, Simona. Financing knowledge-intensive enterprises: Evidence from CVCs in the US. The Journal of Technology Transfer, 42, p. 338-353, 2017. Disponível em: https://link.springer.com/article/10.1007/s10961-016-9495-2. Acesso em: 21 abr.2021.

ROY, Satanik. How technology is changing the face of the startup ecosystem. Your Story, 2018. Disponível em: https://yourstory.com/2018/08/technology-driveinnovation-startup-ecosystem/amp. Acesso em: 10 mar. 2020. 
SANCHES, Vander Lúcio. A importância do empreendedorismo para o desenvolvimento econômico no Brasil, 2018. Disponível em: https://www.nucleodoconhecimento.com.br/administracao/desenvolvimentoeconomico\#3-Metodologia. Acesso em: 24 maio 2019.

SHAPIRO, Carl. Premiums for high quality products as returns to reputations. The Quarterly Journal of Economics, vol. 98, n. 4, p. 659-679, 1983. Disponível em: https://www.jstor.org/stable/1881782?seq=1. Acesso em: 18 abr. 2021.

STARTSE. O que é B2B? E B2C? Aprenda quais os tipos de negócio e como funcionam, 2021. Disponível em: https://app.startse.com/artigos/o-que-e-b2b-e-b2caprenda-quais-os-tipos-de-negocio-e-como-funcionam. Acesso em: 25 fev.2021.

WALSH, Steven T.; LINTON, Jonathan. Infrastructure for emerging markets based on discontinuous innovations, Engineering Management Journal,12, p. 23-31, 2015. Disponível

em: https://www.researchgate.net/publication/277619961_Infrastructure_for_Emergent_In dustries_Based_on_Discontinuous_Innovations. Acesso em: 17 abr. $20 \overline{2} 1$.

SCHUMPETER, J. A. A Teoria do Desenvolvimento Econômico: uma investigação sobre lucro, capital, crédito, juro e o ciclo econômico. Rio de Janeiro: Nova Cultural, 1997. Disponível em: https://www.ufff.br/oliveira junior/files/2009/06/s Schumpeter Teoria do Desenvolvimento Econ\%C3\%B4mico -

Uma Investiga\%C3\%A7\%C3\%A3o sobre Lucros Capital Cr\%C3\%A9dito Juro e Ciclo Econ\%C3\%B4mico.pdf. Acesso em: 15 abr. 2020. 